UCRL-ID-104179

\title{
Lawrence Livermore National Laboratory Post-Loma Prieta Earthquake Initiative: Seismic Analysis of an Elevated Portion of the Bay Bridge Distribution System Structure
}

\author{
D. McCallen \\ G. Goudreau
}

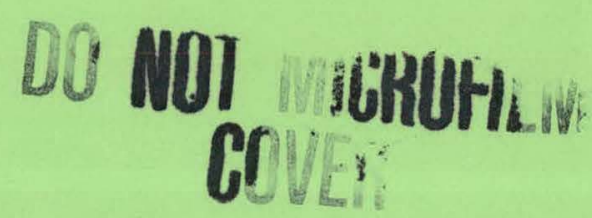

June 1990

This is an informal report intended primarily for internal or limited external distribution. The opinions and conclusions stated are those of the author and may or may not be those of the Laboratory.

Work performed under the auspices of the U.S. Department of Energy by the Lawrence Livermore National Laboratory under Contract W-7405-Eng-48. 


\section{DISCLAIMER}

This report was prepared as an account of work sponsored by an agency of the United States Government. Neither the United States Government nor any agency Thereof, nor any of their employees, makes any warranty, express or implied, or assumes any legal liability or responsibility for the accuracy, completeness, or usefulness of any information, apparatus, product, or process disclosed, or represents that its use would not infringe privately owned rights. Reference herein to any specific commercial product, process, or service by trade name, trademark, manufacturer, or otherwise does not necessarily constitute or imply its endorsement, recommendation, or favoring by the United States Government or any agency thereof. The views and opinions of authors expressed herein do not necessarily state or reflect those of the United States Government or any agency thereof. 


\section{DISCLAIMER}

Portions of this document may be illegible in electronic image products. Images are produced from the best available original document. 


\section{DISCLAIMER}

This document was prepared as an account of work sponsored by an agency of the United States Government. Neither the United States Government nor the University of California nor any of their employees, makes any warranty, express or implied, or assumes any legal liability or responsibility for the accuracy, completeness, or usefulness of any information, apparatus, product, or process disclosed, or represents that its use would not infringe privately owned rights. Reference herein to any specific commercial products, process, or service by trade name, trademark, manufacturer, or otherwise, does not necessarily constitute or imply its endorsement, recommendation, or favoring by the United States Government or the University of California. The views and opinions of authors expressed herein do not necessarily state or reflect those of the United States Government or the University of California, and shall not be used for advertising or product endorsement purposes.

\footnotetext{
This report has been reproduced directly from the best available copy.
}

Available to DOE and DOE contractors from the Utfice of Scientific and Technical Information P.O. Box 62, Oak Ridge, TN 3783 1

Prices available from (615) 576-8401, FTS 626-8401.

Available to the public from the National lechnical Information Service

U.S. Department of $\mathrm{Commerce}$ 5285 Port Royal Rd. Springfield, VA 2216

\section{Papercopy Prices}

A02

$\mathrm{A} 03$

A04

A05

A06

A07

A08

A09

A10

A11

A12

A13

A14

A15

A16

A17

A18

A19

A20

A21

A22

A23

A24

A25

A99
1- 10

11- 50

51- 75

76-100

101-125

126-150

151-175

176-200

201-225

226-250

251-275

276-300

301-325

326-350

351-375

376-400

401-425

426-450

451-475

476-500

501-525

526-550

551-575

576-600

$601 \&$ UP 
UCRL-ID--104179

DE9 0013518

\section{Lawrence Livermore National Laboratory}

Post-Loma Prieta Earthquake Initiative

Seismic analysis of an elevated portion of the

Bay Bridge distribution system structure

David McCallen ${ }^{(1)}$

Gerald Goudreau ${ }^{(2)}$

(1) Structural Mechanics Group, Nuclear Test Engineering Division

(2) Methods Development Group, Nuclear Explosives Engineering Division 


\section{Table of Contents}

Topic

Page

1.0 Background 2

2.0 I80-1580 Distribution Structure 7

3.0 Finite Element Model of the Structure 8

4.0 Modeling Idealizations 9

5.0 Natural Modeshapes of the Roadway Structure 17

6.0 Linear Transient Response to the Oakland Wharf 21 Loma Prieta Earthquake Time History

7.0 Nonlinear Transient Response to the Oakland Wharf 28 Loma Prieta Earthquake Time History

8.0 Summary and Observations 31 Acknowledgements 34

References 35 


\subsection{Background}

The San Andreas fault, which is the most well known and identifiable earthquake fault in the world, extends 800 miles along the western portion of the state of California. The San Andreas is the major boundary between the Pacific crustal plate and North American plate. The Pacific plate is continuously moving northward relative to the North American plate and earthquakes are generated along the fault as a result of "sticking and slipping" between the plates. In the San Francisco bay area the relative motion between the plates is accommodated by slip along the San Andreas fault, the Hayward fault, the Calaveras fault and other smaller faults (see Fig. 1).

Shortly after 5 PM on October 17, 1989 a magnitude 7.1 earthquake occurred without warning on the San Andreas fault in the vacinity of the Santa Cruz mountains. The epicenter of the quake was approximately 10 miles east of the city of Santa Cruz. The location and extent of fault rupture are indicated in Fig. 2. The large earthquake was felt over an area of approximately 400,000 square miles extending from Los Angeles in the south, to the California-Oregon border in the north, and east to central Nevada. The distribution of the estimated intensities (modified Mercalli scale) in the immediate San Francisco bay area are indicated in Fig. 3. This earthquake, which has been named the Loma Prieta earthquake as a result of the close proximity of the epicenter to mount Loma Prieta, is the largest earthquake to occur on the San Andreas since the great San Francisco earthquake of 1906.

It is instructive to compare the Loma Prieta earthquake, which has been termed a "great earthquake" in the popular press, with the 1906 San Francisco earthquake. The 1906 earthquake (estimated magnitude 8.3) resulted from a rupture of approximately 280 miles of the San Andreas fault (see Fig. 4). The Loma Prieta rupture zone was essentially on the southern most end of the 1906 rupture zone. The total amount of energy released during the 1906 San Francisco earthquake has been estimated to be about 63 times the amount of energy released during the Loma Prieta earthquake ${ }^{[1]}$.

The duration of strong ground motion is a very important factor determining the degree of structural damage which will occur during an earthquake. The longer the duration of the earthquake ground motion, the more cycles of motion the structure will be subjected to. As the structure goes through more cycles, the transient response of each mode of vibration can continue to build. In addition, when nonlinear behavior occurs during strong shaking, stiffness degradation and a reduction in the ability of the structure to dissipate energy through inelastic action may occur. The more nonlinear cycles which the structure is required to endure, the more stiffness degradation may occur with the result being significant damage or collapse. The Loma Prieta earthquake resulted in strong ground shaking of approximately 5 to 10 seconds duration at most locations in the immediate San Francisco 


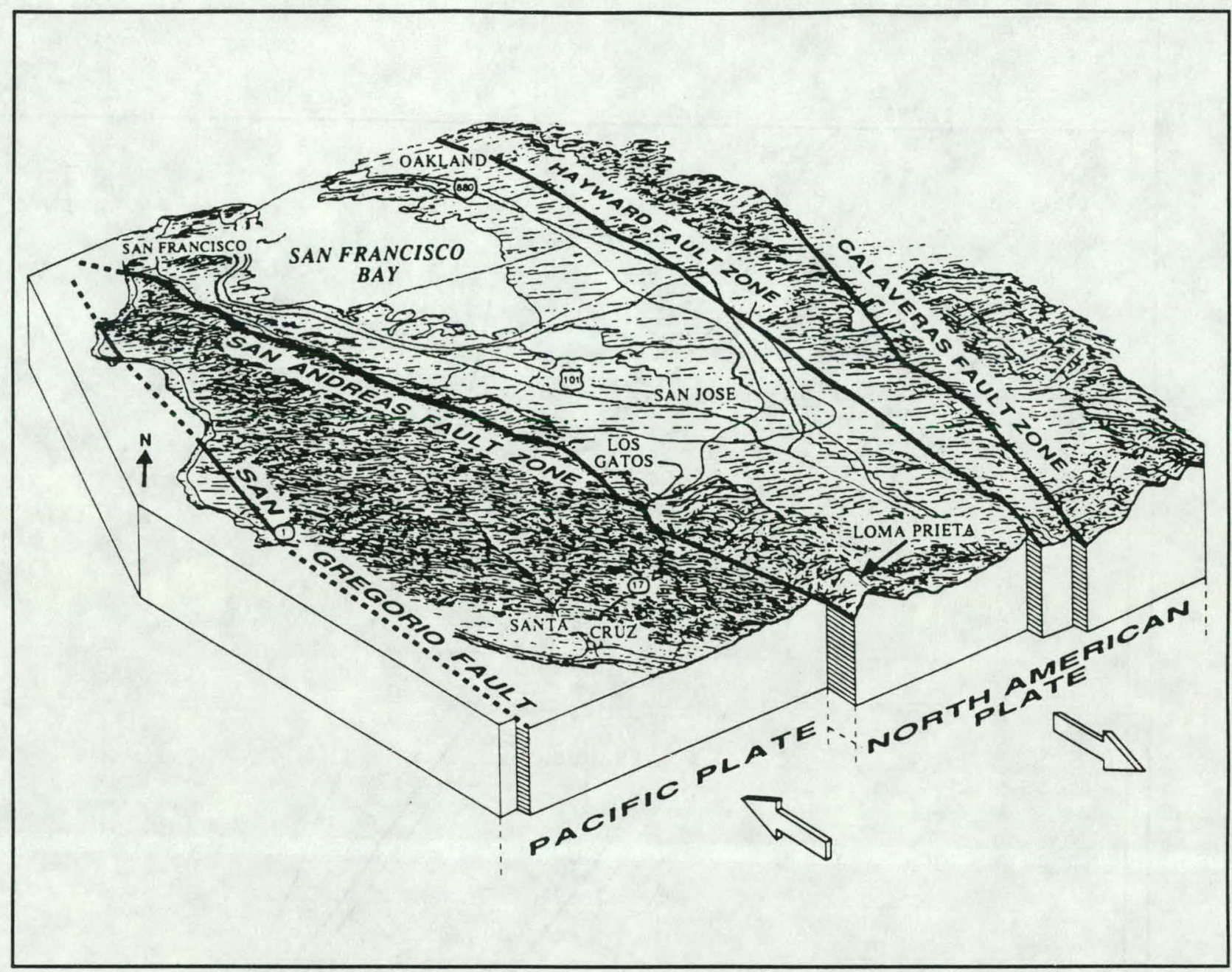

Figure 1. Major Faults in the San Francisco Bay Area

bay area. This is in contrast to the 40 to 45 seconds of strong duration shaking experienced in the 1906 earthquake. In light of this, the damage potential of a 1906 type quake greatly cxceeds the damage potential of a Loma Prieta type earthquake. Professor Bertero of U.C. Berkeley, a leading expert in earthquake engineering, has contended ${ }^{[2]}$ that if the bay area had been subjected to just 5 more seconds of strong ground motion during the Loma Prieta earthquake, "the damage would've been three, four or five times more extensive".

Despite the fact that the damage potential of the Loma Prieta earthquake was relatively small compared to a great 1906 type quake, there was incredible destruction in the few seconds of the quake. The damage totals which resulted from the earthquake include 62 confirmed deaths, approximately 3,700 serious injuries and 18,300 homes heavily damaged. The transportation infrastructure in the immediate San Francisco bay area was particularly hard hit. A segment of the upper deck on the Oakland-San Francisco bay bridge, which is the main artery between the east bay communities and San Francisco, collapsed during the quake. As a result, the bridge was unusable for 1 month and transbay commuters were forced to commute on ferries or the crowded Bay Area Rapid Transit (BART) system. 


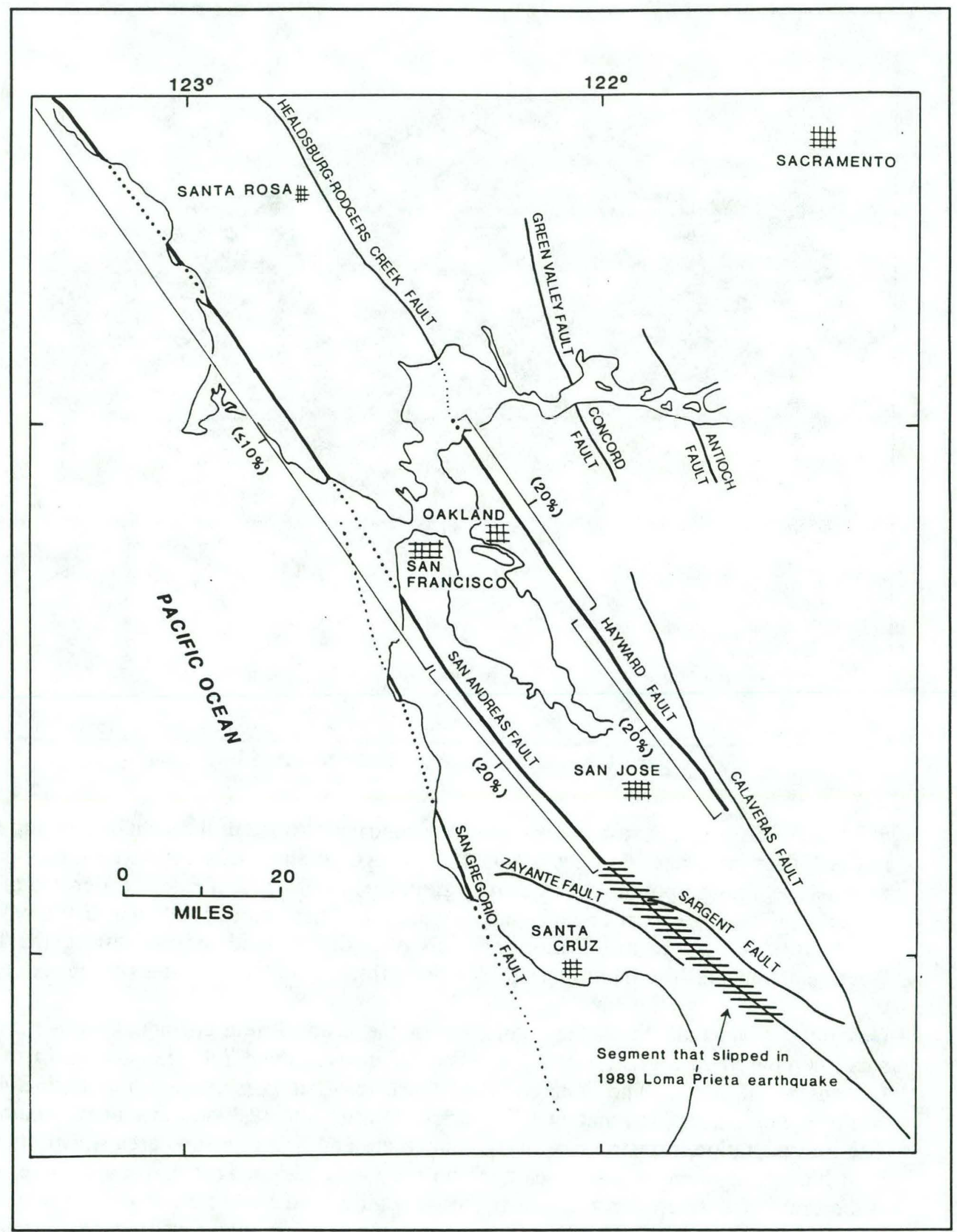

Figure 2. Location of Faulting in Loma Prieta Earthquake 

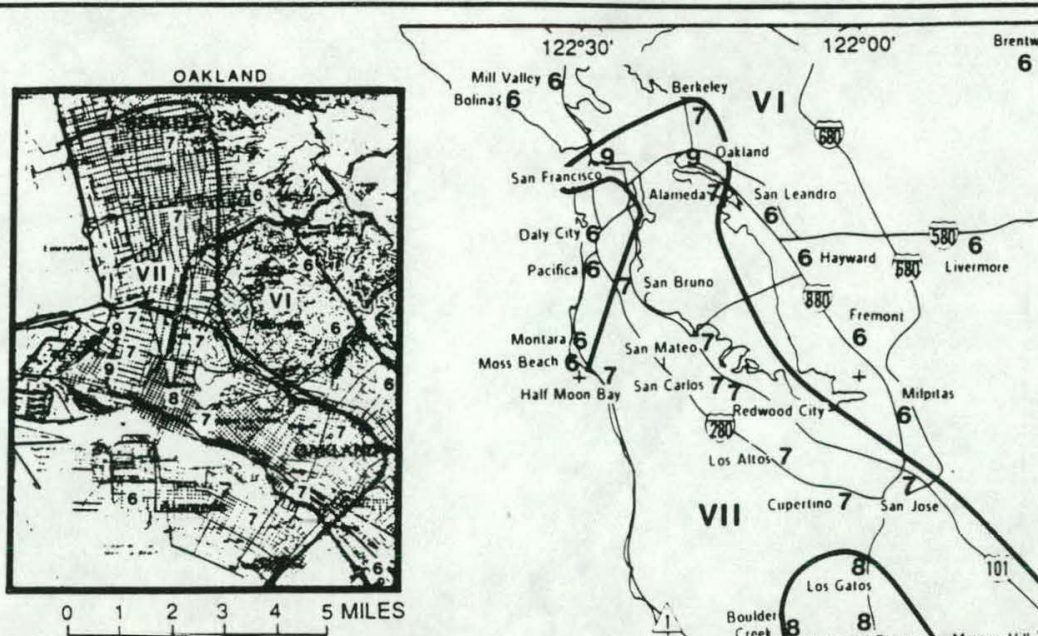

6
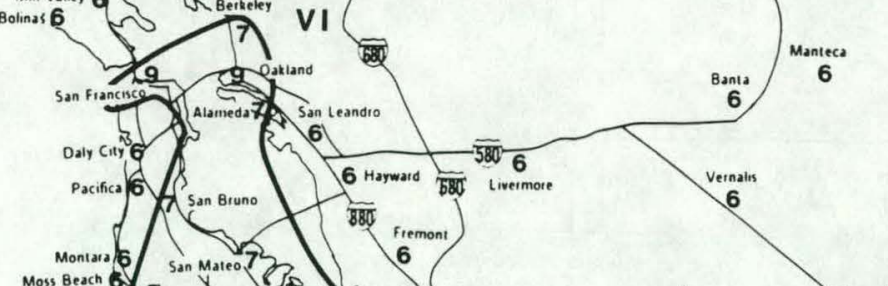

4 2800

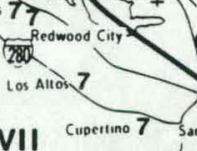

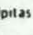

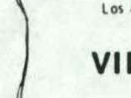

SAN FRANCISCO

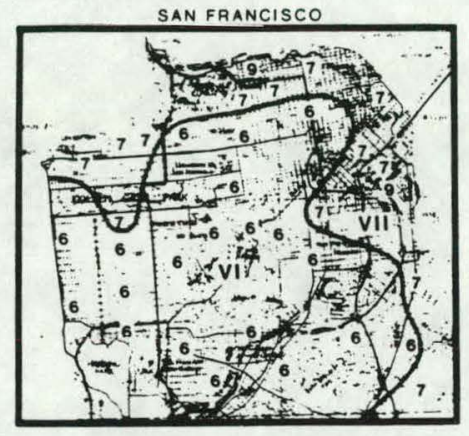

I

(
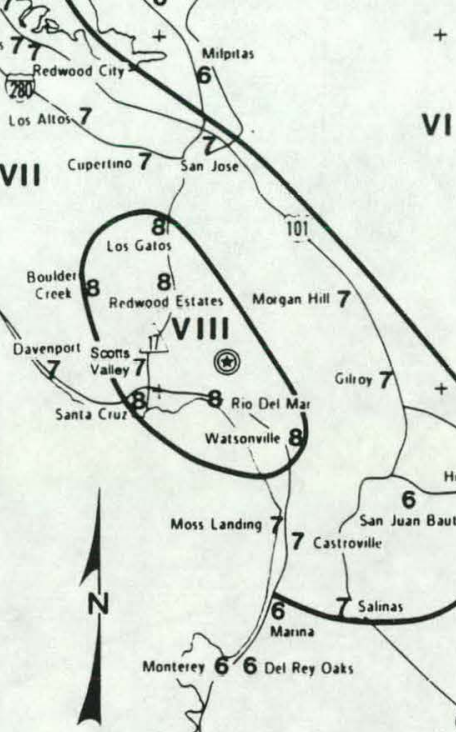

$\begin{array}{llllll}0 & 1 & 2 & 3 & 4 & 5\end{array}$ MILES

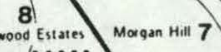

if $\mathrm{VII}$

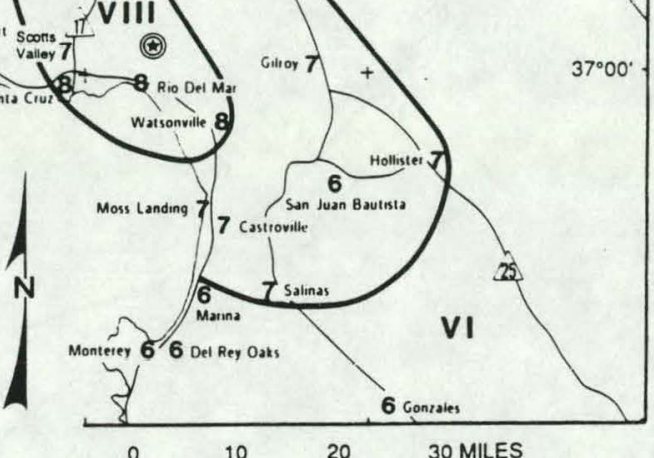

I Not felt by people, except rarely under especially favorable circumstances.

II Felt indoors only by persons at rest, especially on upper floors. Some hanging objects may swing.

III Felt indoors by several. Hanging objects may swing slightly. Vibration like passing of light trucks. Duration estimated. May not be recognized as an earthquake.

IN Felt indoors by many, outdoors by few. Hanging objects swing. Vibration like passing of heavy trucks; or sensation of a jolt like a heavy ball striking the walls. Standing automobiles rock. Windows, dishes, doors rattle. Wooden walls and frame may creak.

V Felt indoors and outdoors by nearly everyone: direction estimated. Sleepers wakened. Liquids disturbed, some spilled. Small unstable objects displaced or upset; some dishes and glassware broken. Doors swing; shutters, pictures move. Pendulum clocks stop, starh, change rate. Swaying of tall trees and poles sometimes noticed.

V Felt by all. Damage slight. Many frightened and run outdoors. Persons walk unsteadily. Windows, dishes. glassware broken. Knickknacks and books fall off shelves; pictures off walls. Furniture moved or overtumed. Weak plaster and masonry cracked.

VII Difficult to stand. Damage negligible in buildings of good design and construction; slight to moderate in well-built ordinary buildings; considerable in hadly designed or poorly built buildings. Noticed by drivers of automobiles. Hanging objects quiver. Furniture broken. Weak chimneys broken. Damage to masonry; fall of plaster, loose bricks, stones, tiles, and unbraced parapets. Small slides and caving in along sand or gravel banks. Large bells ring.
VIII People frightened. Damage slight in specially designed structures; considerable in ordinary substantial buildings, partial collapse; great in poorly built structures. Steering of automobiles affected. Damage or partial collapse to some masonry and stucco. Failure of some chimneys, factory stacks, monuments, towers, elevated tanks. Frame houses moved on foundations if not bolted down; loose panel walls thrown out. Decayed pilings broken off. Branches broken from trees. Changes in flow or temperature of springs and wells. Cracks in wet ground and on steep slopes.

IX General panic. Damage considerable in specially designed structures; great in substantial buildings, with some collapse. General damage to foundations; frame structures, if not bolted, shifted off foundations and thrown out of plumb. Serious damage to reservoirs. Underground pipes broken. Conspicuous cracks in ground; liquefaction.

$X$ Most masonry and frame structures destroyed with thcir foundations. Some well-built wooden structures and bridges destroyed. Serious damage to dams, dikes, embankments. Landslides on river banks and steep slopes considerable. Water splashed onto banks of canals, rivers, lakes. Sand and mud shifted horizontally on beaches and flat land. Rails bent slightly.

XI Few, if any masonry structures remain standing. Bridges destroyed. Broad fissures in ground: earth slumps and landslides widespread. Underground pipelines completely out of service. Rails bent greatly.

XII Damage nearly total. Waves seen on ground surfaces. Large rock masses displaced. Lines of sight and level distorted. Objects thrown upward into the air.

Figure 3. Modified Mercalli Intensities in the Bay Area 


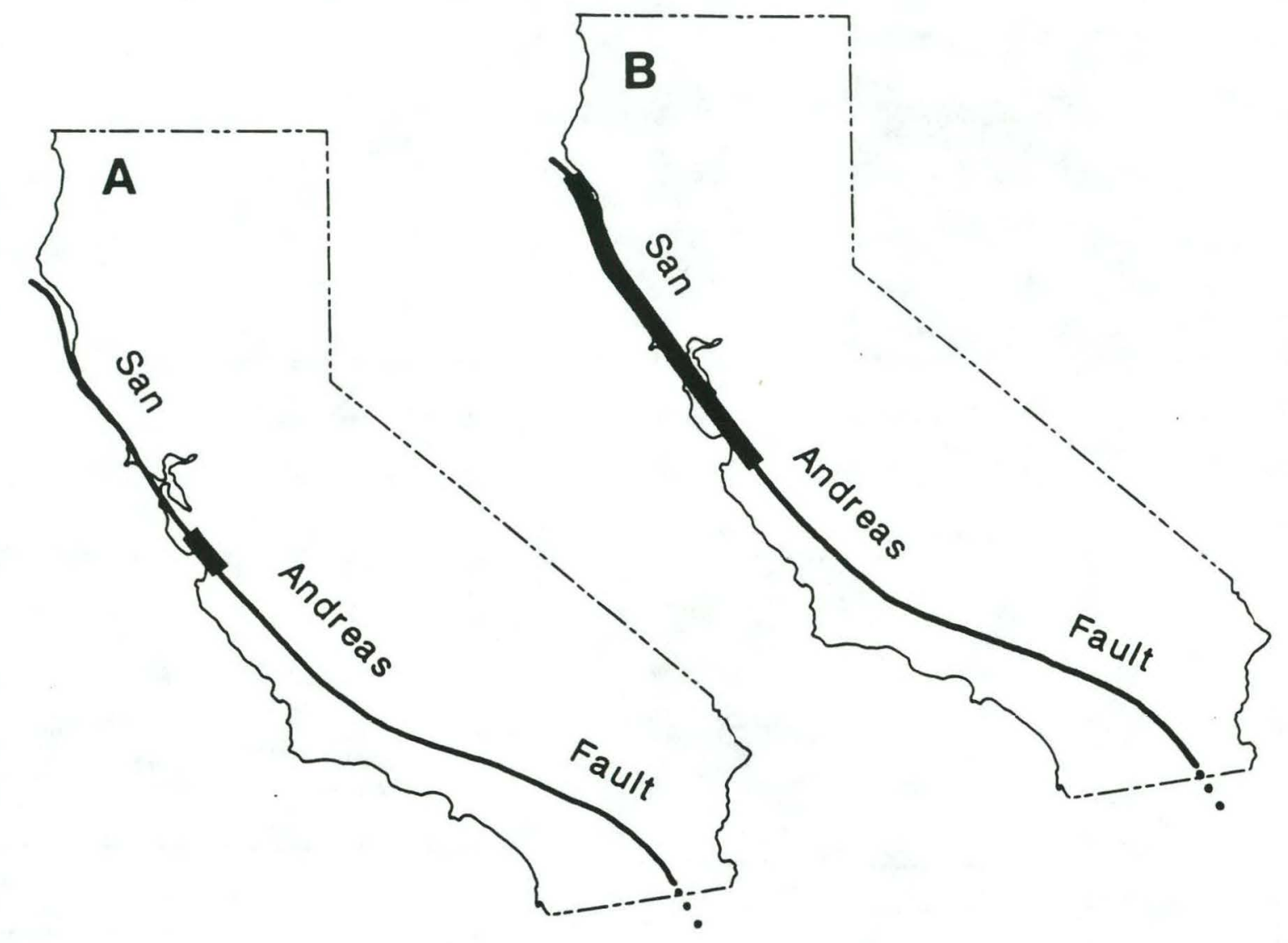

Figure 4. Comparison of 1989 and 1906 Rupture Zones

Approximately 1.5 miles of the reinforced concrete elevated double deck roadway of the I880 freeway (a.k.a the Cypress structure) completely collapsed during the quake. The Cypress structure collapse accounted for nearly $2 / 3$ of the fatalities during the quake. The San Mateo bridge was slightly damaged and was closed temporarily for inspection and repairs. The Embarcadero double deck elevated roadway structure in San Francisco (which is similar in construction to the Cypress structure) was heavily damaged during the quake. After much debate, centered on the economic impacts to nearby communities, the mayor and city council of San Francisco have endorsed a plan to demolish the Embarcadero structure and replace it with an underground roadway. Transportation structures in the Santa Cruz and Watsonville area were also heavily damaged. The Struve Slough bridge on Highway 1, for example, suffered a complete collapse.

The economic reverberations of the Loma Prieta earthquake are still being felt. Tourism in the San Francisco area is down as much as 30 percent and it appears that additional economic impact, above and beyond the original damage cost estimate of 6 billion, will result. 
Because of the importance of earthquake safety for the citizens of California, and the potential devastating effects of future large earthquakes on the California economy, upper management at the Lawrence Livermore National Laboratory (LLNL) made a decision that LLNL should make available any unique laboratory resources to aid in post-earthquake studies. One area in which LLNL has attempted to help is in computer simulation of the performance of large scale transportation structures. The computer horsepower available at LLNL, coupled together with the in-house finite element software capabilities, results in a unique numerical simulation capability for large structures. The effort summarized in this report is one of a number of post-earthquake efforts at LLNL. The financial support for this project was provided by the LLNL Engineering Department.

\subsection{I80-I580 Distribution Structure}

The structure which connects 180 to I580 in the distribution system on the east end of the Oakland-San Francisco bay bridge consists of a 28 foot wide elevated segment of roadway. The elevated structure is a steel and concrete hybrid structure and consists of a reinforced concrete deck which is supported on wideflange stringer beams. The deck structure and stringer beams span between steel plate girder bents, which are supported on a single reinforced concrete column (there is one nontypical bent which has two columns). One end of the elevated structure ends at a reinforced concrete abutment, and the other end merges with an adjacent elevated roadway segment. The location of the structure relative to other structures which were heavily damaged in the earthquake is shown in Fig. 5.

The California Strong Motion Instrumentation Program (CSMIP), administered by the California Department of Mines and Geology, has responsibility for providing earthquake instrumentation on significant structures located in key seismic regions throughout the state. The CSMIP has an extensive strong motion measuring array in the San Francisco bay area and Loma Prieta ground motion records were recorded at 93 stations ${ }^{[3]}$. The peak ground acceleration (pga) values measured for the Loma Prieta earthquake by the CSMIP stations in the immediate San Francisco area are shown in Fig. 5. The pga values illustrate very pronounced local site effects on the observed intensity of ground shaking. The accelerations observed on stiff rock sites (e.g. Yerba Buena island) were on the order of $0.06 \mathrm{~g}$. Accelerations observed at sites with poor soil conditions were significantly larger. A number of locations near the waterfront, where saturated soils of poor structural quality typically exist, exhibited pga values in the $0.3 \mathrm{~g}$ range. The CSMIP station located nearest the east end of the Bay Bridge was at the Oakland outer harbor wharf (the location indicating $0.29 \mathrm{~g}$ in Fig. 5). Additional stations in the near vacinity include a station near Lake Merritt (the 0.26g station in Fig. 5) and a USGS station just north of the Bay Bridge (not shown in Fig. 5) which measured a pga of approximately $0.3 \mathrm{~g}$. The commonality of all of these nearby records is that relatively large accelerations were observed in the 
area near the distribution structure. Because the records from the various stations were in good agreement with respect to pga values, it was decided, based on discussions with

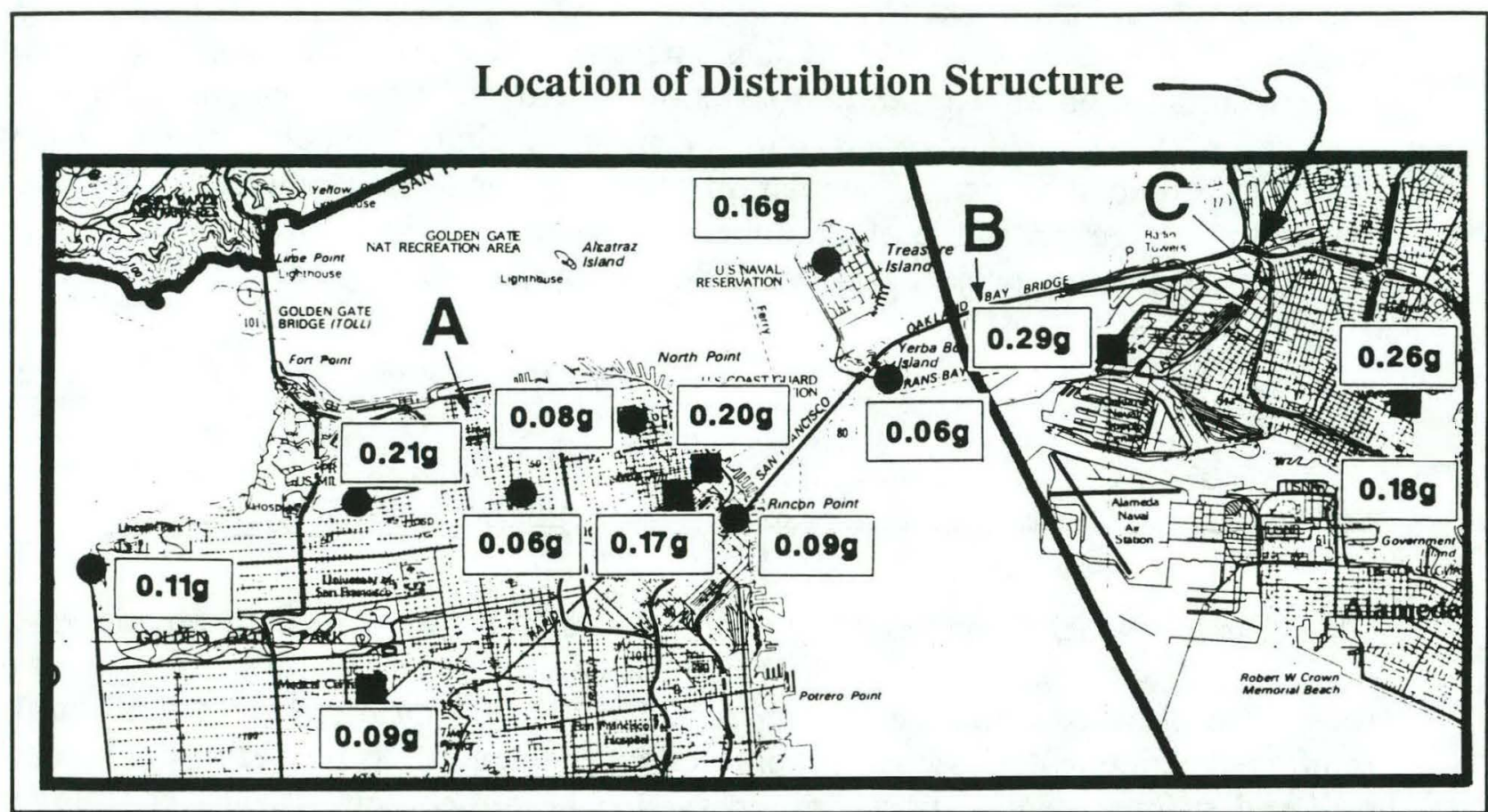

Figure 5. CSMIP Array Peak Ground Accelerations

U.C. Berkeley researchers, that the free field time histories measured at the outer harbor wharf would be fairly representative of the motion which the distribution structure was subjected to.

\subsection{Finite Element Model of the Structure}

Two detailed finite element models of the distribution structure were generated with the LLNL computer program SLIC ${ }^{[4]}$. The first model was constructed for the implicit, finite deformation nonlinear finite element program NIKE3D ${ }^{[5]}$. The NIKE3D program utilizes the Hughes-Liu shell element ${ }^{[6]}$ and a Hughes-Liu beam element which is constructed by degeneration of the shell. Nonlinear material behavior for both elements is handled by performing through-thickness integrations in addition to integrations along the length dimensions of the shell and beam. The second model was generated for the linear elastic small deformation finite element program GEMINI ${ }^{[7]}$. GEMINI is a modernized version of the SAPIV finite element program. GEMINI employs the Archer linear beam element and a linear Hughes-Liu shell element. The GEMINI model was constructed primarily to perform a check on the modeshapes and frequencies obtained with NIKE3D. 
The finite element model geometry for the roadway is shown in Fig.s 6, 7 and 8. The structure transitions through four horizontal curves and has a variation in elevation throughout its length. Significant nontypical features of the bridge include a nontypical two column bent located about two thirds of the way down the bridge, and one span which is significantly longer than any of the other spans (see Fig. 8). The double column bent and long span section both accommodate railway sections which pass under the bridge.

\subsection{Modeling Idealizations}

A number of simplifying assumptions and idealizations were utilized in the generation of the finite element models. Some of the assumptions were made in an effort to expedite the model generation without sacrificing the utility of the results. Other assumptions were made to limit the size of the model and render a model for which both linear and nonlinear analyses were feasible. Assumptions which were aimed at economizing the model generation include:

- An assumption of uniform roadway superelevation throughout the length of the structure:

Based on conversations with Caltrans engineers, it was decided that the use of a nominal, constant roadway superelevation throughout the length of the structure was adequate. The actual superelevation varies from about $8 \%$ in the tightest curves to $2 \%$ in the straightest sections of the roadway. In the model a nominal superelevation of $4 \%$ was used throughout.

- Nominal column, stringer beam and plate girder dimensions were utilized throughout the length of the structure:

Nominal section dimensions were utilized so that typical sections could be copied and replicated throughout the length of the roadway. It was felt that this assumption would not significantly effect the distribution of reactions in the structural elements.

- The reinforced concrete columns were idealized as linear elastic elements with dimensions equal to the overall dimensions of the column and a modulus of elasticity representative of $\mathbf{4 0 0 0}$ psi concrete was used:

Representation of columns in this fashion is equivalent to modeling an uncracked, nontransformed section. 


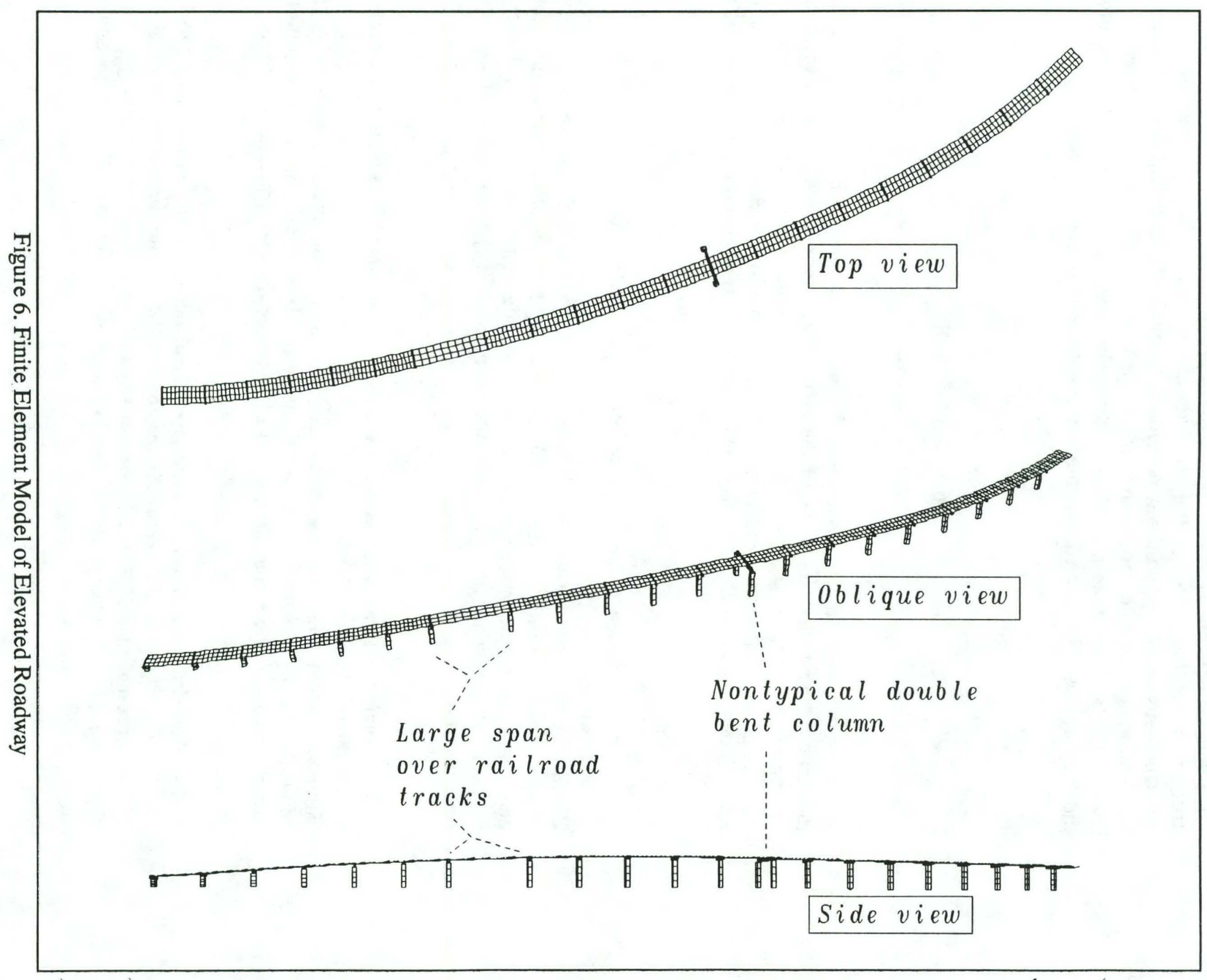




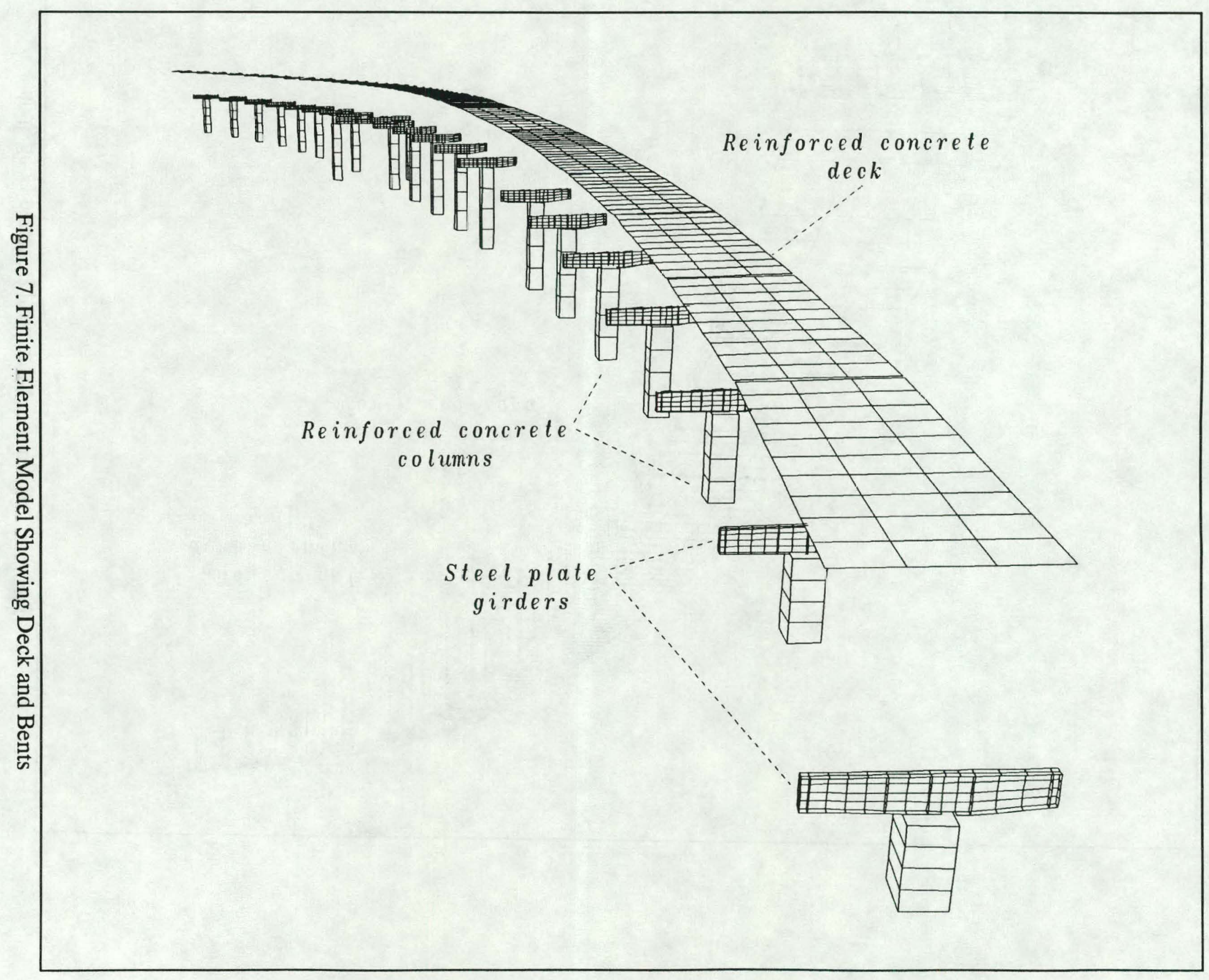




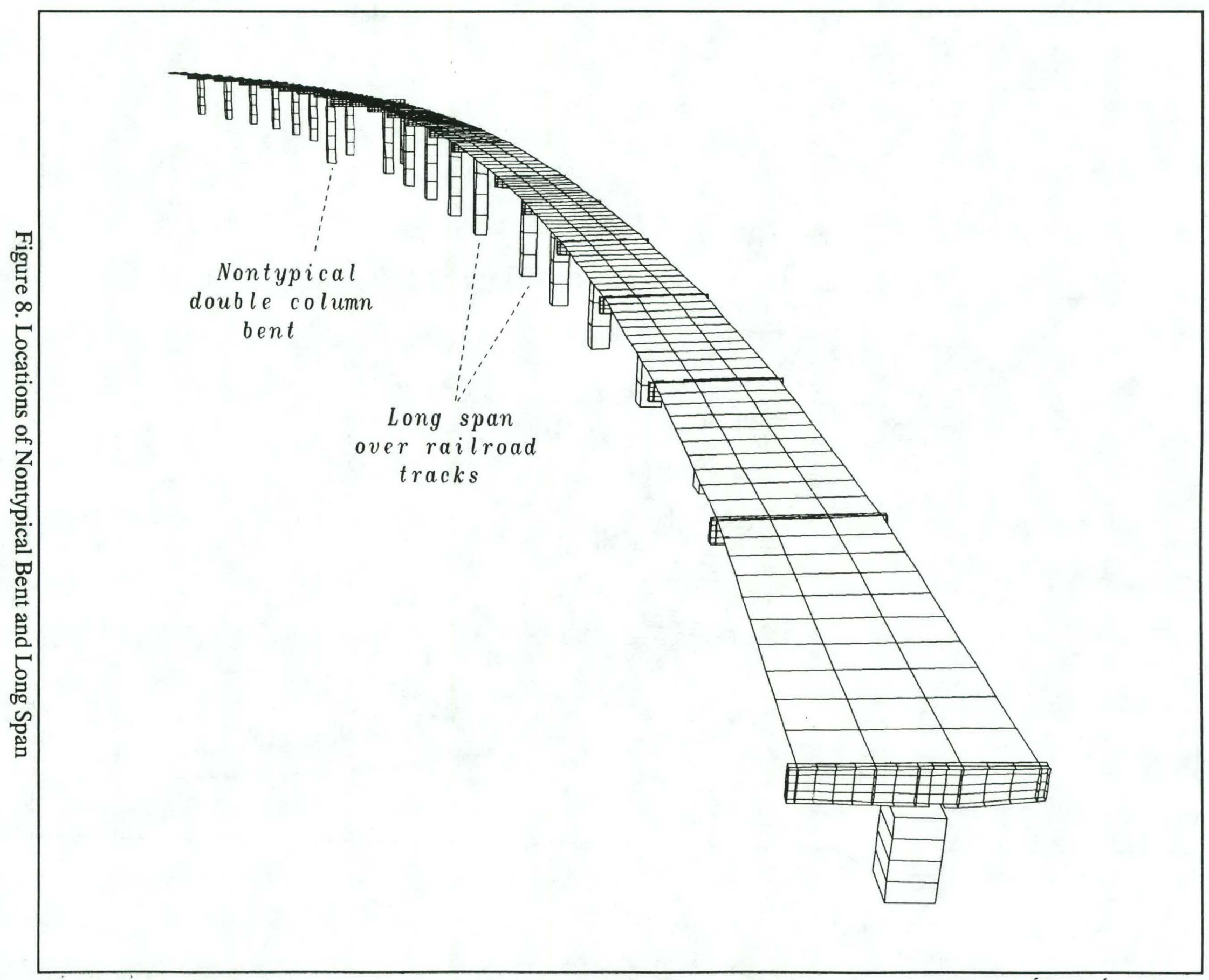


The columns were assumed fixed against translations and rotations at the column bases. Thus a fixed base model was assumed for the analyses discussed herein. If information becomes available on soil properties at the site, lumped spring idealizations of the soil compliance could be added at the hase of the columns (with the effect of lowering the modal frequencies).

- The primary idealization used to reduce the model size was the representation of the columns with beam elements:

The actual columns have a dimensionally large cross section. Representation of the columns with a beam element based on line diagram geometry neglects the stiffening effect of the finite size joint. In order to capture the stiffening effect of the finite dimensions of the column cross section at the column/plate girder connection, a cross of artificially stiff beam elements was attached to the base of the plate girder. Based on our conversations with researchers at U.C. Berkeley ${ }^{[8]}$ it was decided that the beam element idealization should be verified in light of the large cross sectional dimensions of the actual columns.

In order to check the column idealization, an example problem was generated in which a single bent was modeled first with a coarse model, with a beam element idealization of the columns, and second with a detailed 3-d model in which solid elements were used to model the column with the actual column dimensions. The coarse model is shown in Fig. 9 and the detailed model is shown in Fig. 10. In both cases the plate girder is modeled using shell elements. To verify the ability of the coarse model to adequately represent the force-displacement behavior of the column/bent structure, the two models were compared for a point lateral loading of 10,000 pounds. The displacement of each model for the prescribed loading is shown in Fig. 11. There is a good correlation between the coarse and detailed models and thus the coarse model correctly represents the stiffness of the column/bent structure.

The precise boundary conditions to be utilized in the finite element model are very difficult to define. At the end of the bridge which terminates at the abutment there is the potential for very complex nonlinear interaction between the bridge and the abutment structure. At the end of the bridge which merges with the adjacent structure, there will be an interaction with the adjacent elevated roadway structure. The scope of the current analyses did not encompass modeling of the adjacent structure or treatment of the nonlinear contact at the abutement. NIKE3D does have nonlinear contact capabilities, however, it appears that there is little or no data for verification of existing methodologies for handling nonlinear contact at abutments ${ }^{[9]}$.

Because of the nebulous nature of the boundary conditions for the structure, two different sets of boundary conditions were considered. In the first case it was assumed that the structure under consideration receives solid support from the structures on both ends. For this case all translations were removed along the base of the plate girder at the abutment 


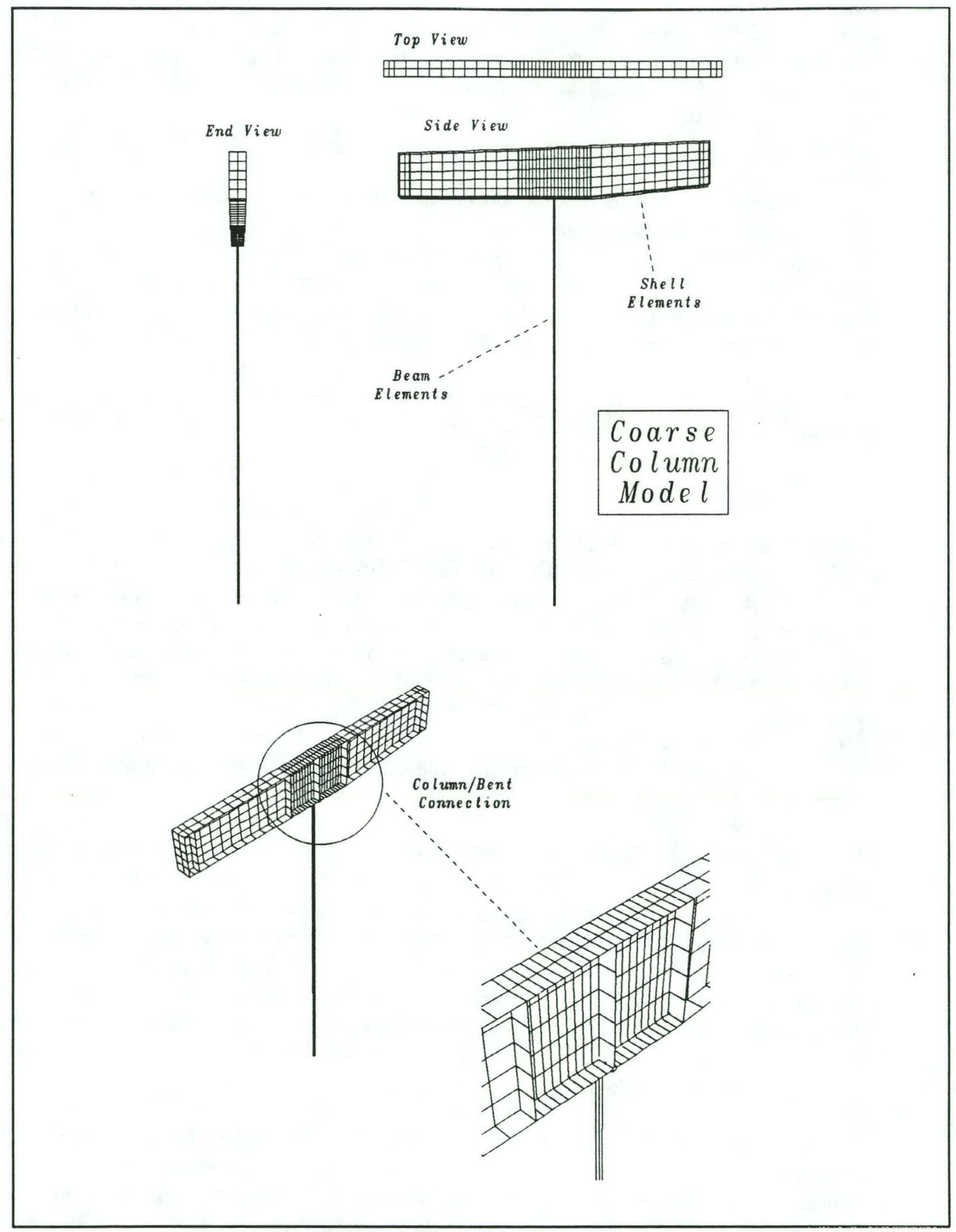

Figure 9. Coarse Model of Bent Structure 


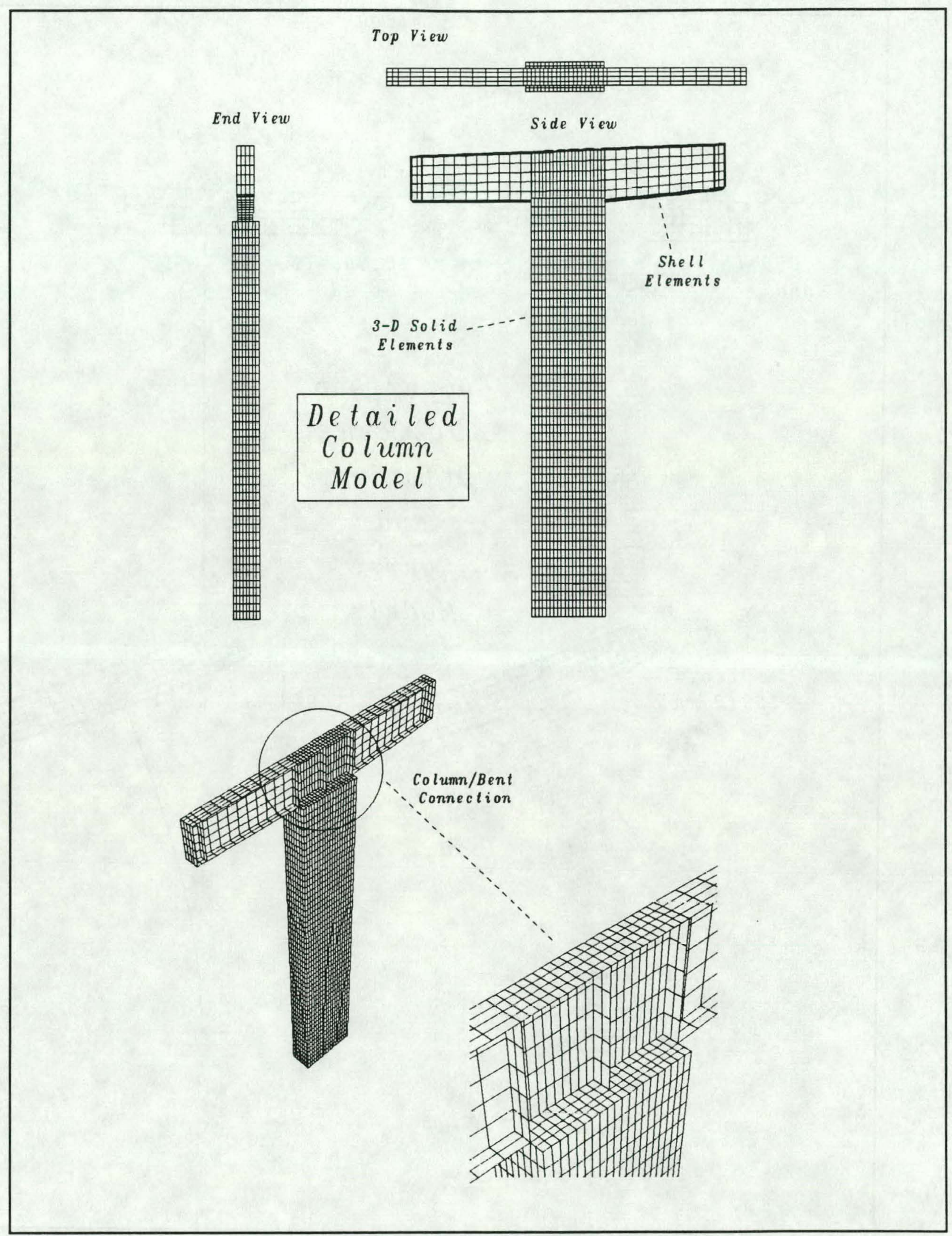

Figure 10. Detailed Model of Bent Structure 

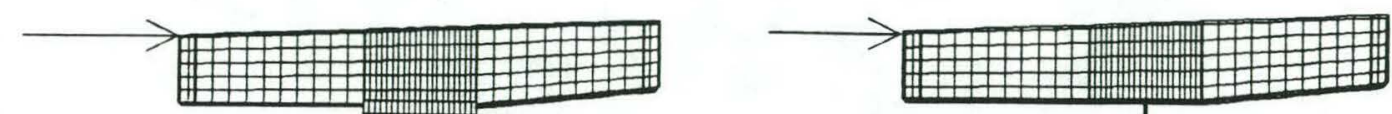

$10,000 l b$. Load

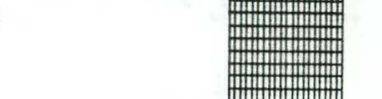

$10,000 l b$. Load

Comparison

Be twe en

Detailed

and

Coarse

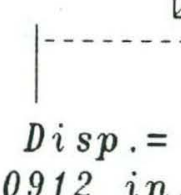

m册m

.0912 in.

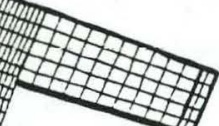

Models

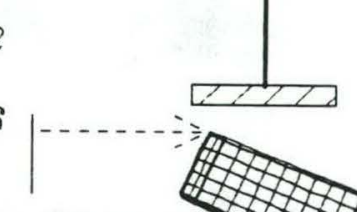

Disp.=

$.0913 \mathrm{in}$.

Figure 11. Comparison of Coarse and Detailed Models 
end, and all displacements and rotations were removed in the deck at the location where the deck couples to the adjacent structure. In the second case it was assumed that only vertical displacement was prevented at the abutment end and that only vertical displacement was prevented at the end where the deck couples into the adjacent structure.

The two boundary condition cases described represent extremes of support at the ends of the elevated roadway. In the first case lateral loads can be resisted by shears which develop in the roadway deck at each end of the structure. In the second case, lateral load must be entirely resisted by the shears developed at the base of the columns.

\subsection{Natural Modeshapes of the Roadway Structure}

The first three natural modeshapes of the structure for the the first set of boundary conditions are shown in Fig.s 12, 13 and 14. These figures show modeshapes determined by both NIKE3D and GEMINI. The first mode consists of vertical vibration of the long span segment of the deck. NIKE3D and GEMINI are in substantial agreement for this mode with NIKE3D predicting a frequency of $1.636 \mathrm{Hertz}$ and GEMINI predicting a frequency of 1.603 Hertz. The spatial distributions of the modeshapes are also quite similar. It should be noted that when this particular mode is animated on the computer with a large displacement scale factor, a displacement component consisting of rocking of the entire deck assembly is also visible. This rocking component is not visible in the hardcopy plot shown in the figures because it is very small compared to the transverse motion of the long span deck segment. The second predicted mode of the structure for the first boundary condition case consists of rocking and translation of the deck (Fig. 13). The predominant motion occurs at the tallest location of the bridge where the structure is more flexible. The NIKE3D and GEMINI models agree well, with the NIKE3D model predicting a frequency of $1.864 \mathrm{Hertz}$ and GEMINI predicting a frequency of $1.807 \mathrm{Hertz}$. The modeshape plots show that the long span deck segment in the NIKE3D model appears to be slightly less flexible than the corresponding deck segment in the GEMINI model. This is attributable to the fact that NIKE3D can currently only handle rectangular and circular beam elements. When representing a nonrectangular wide flange beam with the NIKE3D beam element, the beam dimensions can be selected such that the bending inertias about the principal axes are correct. However, the torsional stiffness and axial stiffness will, in general, be incorrect. The torsional stiffnesses of the beam elements which represent the deck stringer beams in the NIKE3D model are too stiff and the twisting observed in the long span of the deck is somewhat less than the deck twisting observed in the GEMINI model. The third modes predicted by the two programs are shown in Fig. 14. The GEMINI model predicted a frequency of $1.914 \mathrm{Hertz}$ and the NIKE3D model predicted a frequency of $1.979 \mathrm{Hertz}$ and the spatial distributions of the modeshapes are in good agreement. 


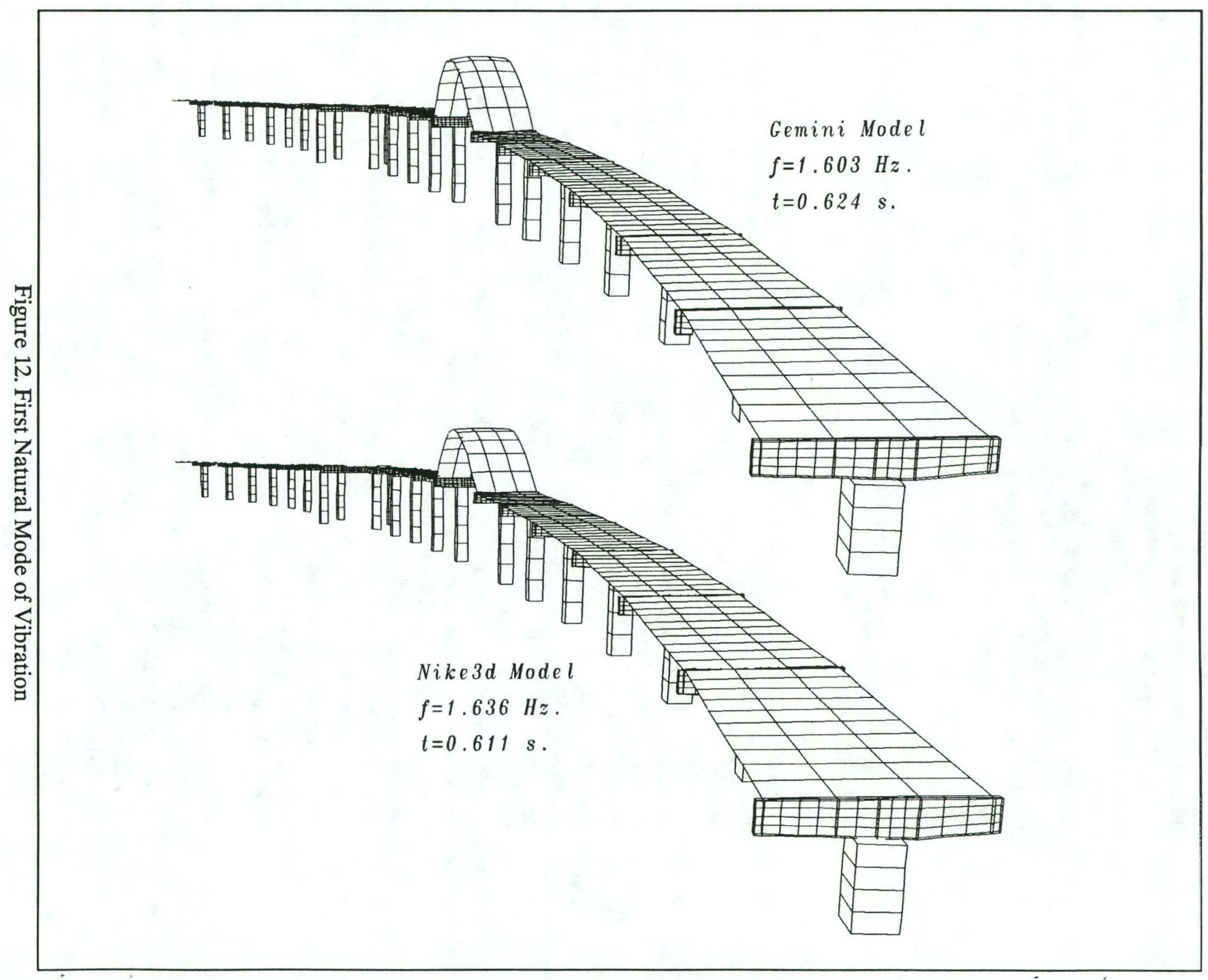




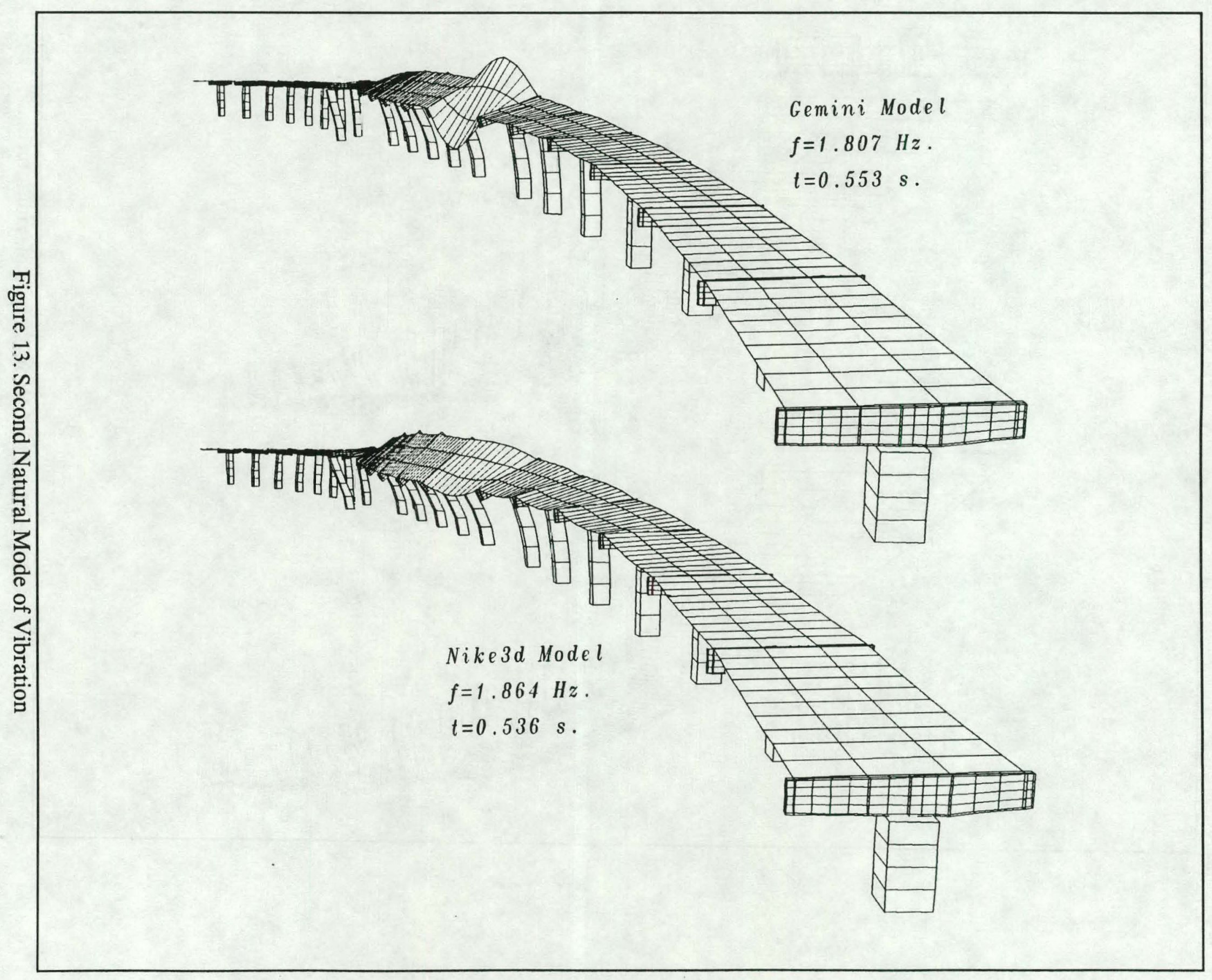




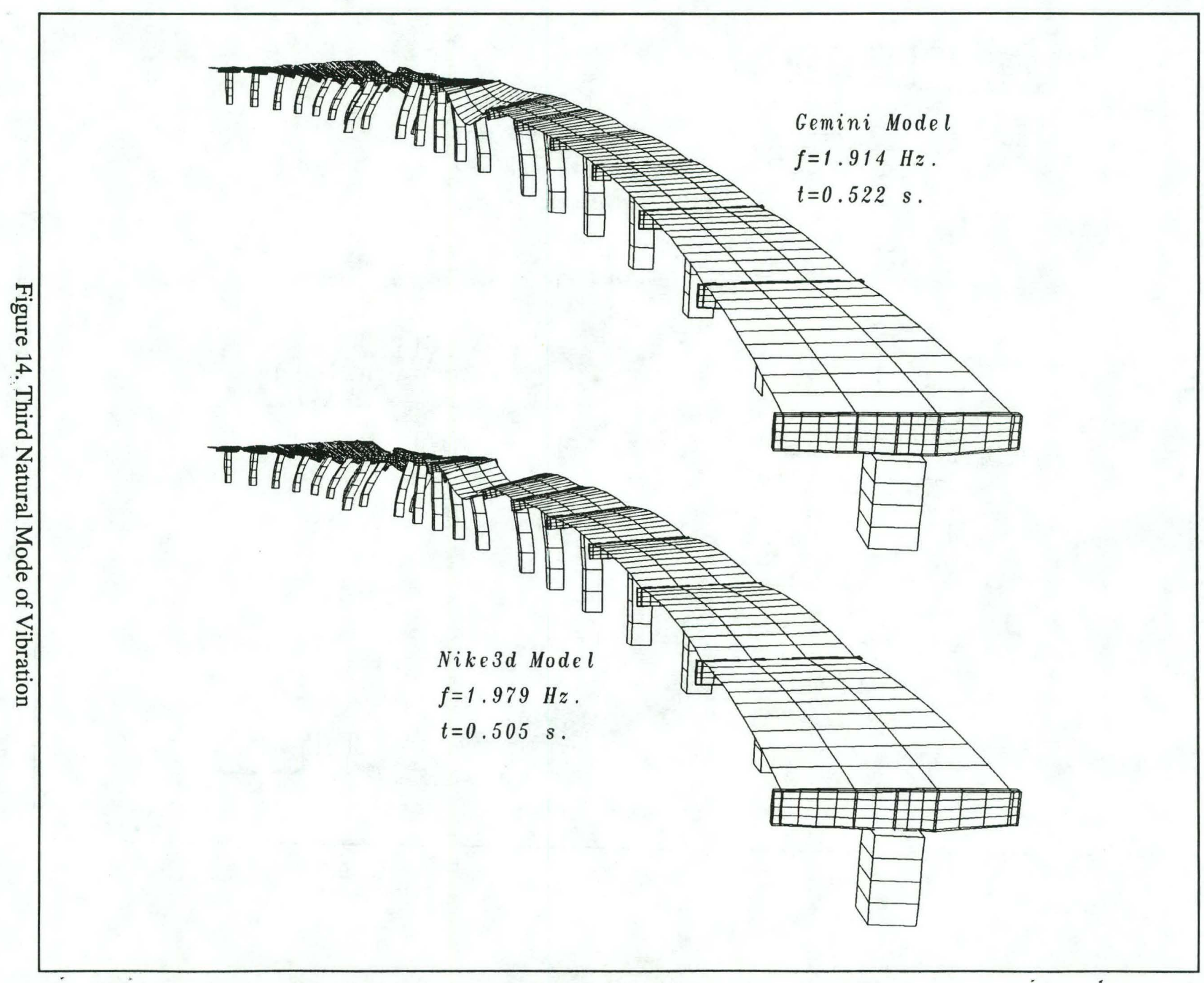


For the second boundary condition case the modeshapes which were determined by the NIKE3D program are shown in Fig.s 15 through 17. The fundamental mode consists primarily of longitudinal rocking of the entire bridge assembly. The short columns at the abutment end of the bridge are stiff relative to the taller columns and the longitudinal displacement near the short end must be accommodated by out of plane bending of the plate girders. For this mode, the plate girders at the short end are the most severely stressed. The second mode consists of the vertical motion of the long span section (Fig. 16) and the third mode consists of rocking of the deck through the tallest segment of the roadway. The fourth and fifth modes consist of deck translation and rocking and are shown in Fig. 17). It is noted that modes 2,4 and 5 for this boundary condition case correspond to modes 1,2 and 3 from the first boundary condition case.

\subsection{Linear Transient Response to the Oakland Wharf}

Loma Prieta Earthquake Time History

The first transient analysis which was performed considered the linear elastic, small deformation response of the structure to the three components of Loma Prieta earthquake free field ground motion measured at the Oakland wharf. The CSMIP accelerograms measured at the wharf have a total duration of 90 seconds. The strong ground motion, however, occurs in a time span of approximately 10 seconds which runs from about 9 seconds to 19 seconds in the time sequence. For the transient analysis, the structure was only subjected to this 10 second segment of strong ground motion. The 10 second segments which were extracted from each time history component are shown in Fig.s 18, 19 and 20. Both horizontal components of ground motion exhibit peak accelerations of just under $0.3 \mathrm{~g}$ and the maximum vertical acceleration is $0.084 \mathrm{~g}$. Acceleration response spectrums for each component of motion are also shown in Fig.s 18, 19 and 20 for $0 \%$ and $2 \%$ damping. Both horizontal component spectra exhibit frequency content in the period range from 0.5 to 1.0 seconds and both have a slightly less pronounced peak in the 1.3 to 1.5 second range.

The linear transient response was performed with NIKE3D. A direct integration of the equations of motion was performed and NIKE3D utilizes Newmark-Beta temporal integration. NIKE3D is a nonlinear program which performs equilibrium iterations with BroydenFletcher-Goldfarb-Shanno (BFGS) stiffness updates within each load step (or in the case of dynamic analysis in each time step). NIKE3D does not have a special feature for the solution of linear small deformation problems, however, it was found that for the current structure the convergence at each time step was very fast. Typically only one BFGS stiffness update was performed at each load step and convergence was immediate. Thus it was found that NIKE3D could solve the linear problem economically. This is significant be- 


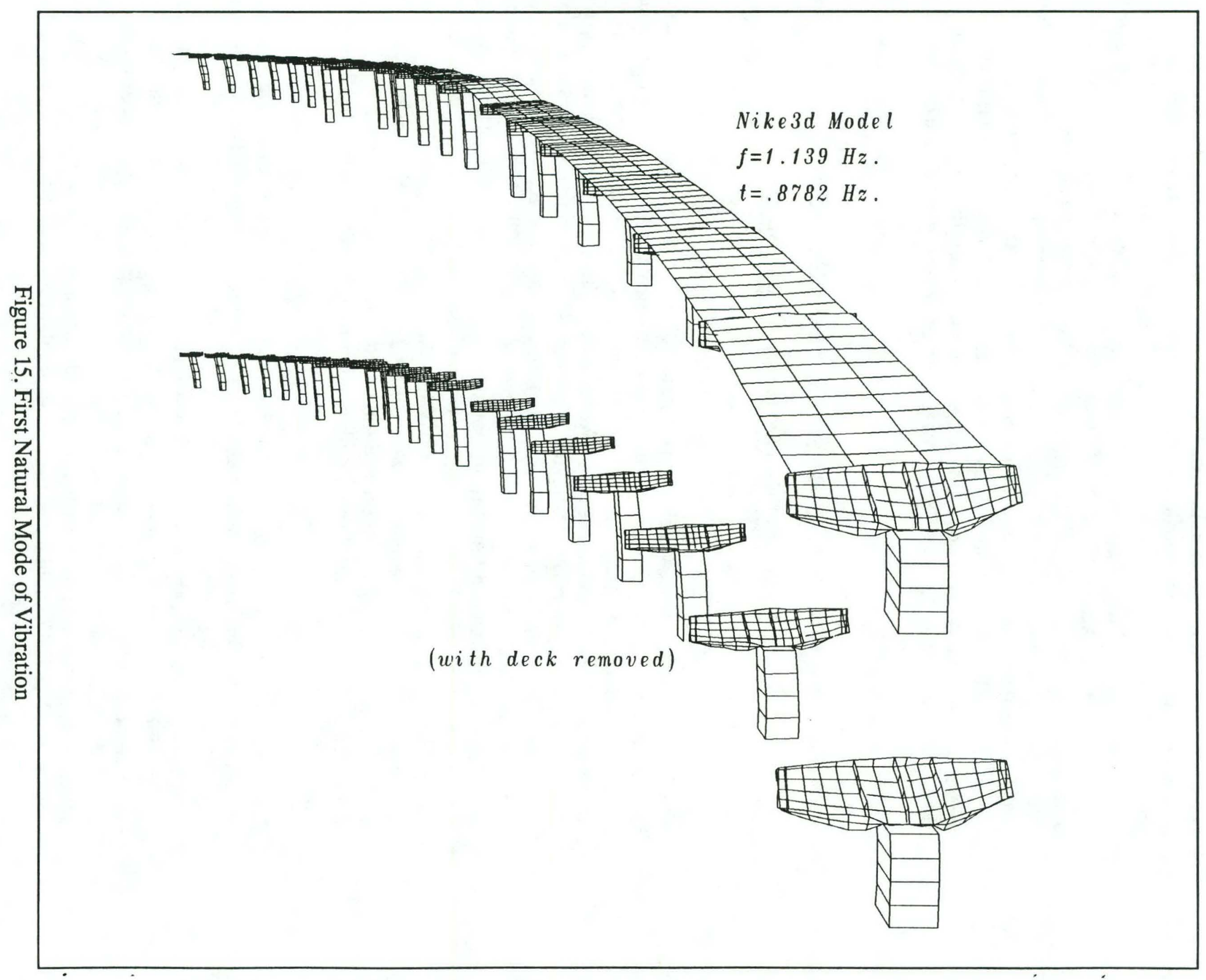




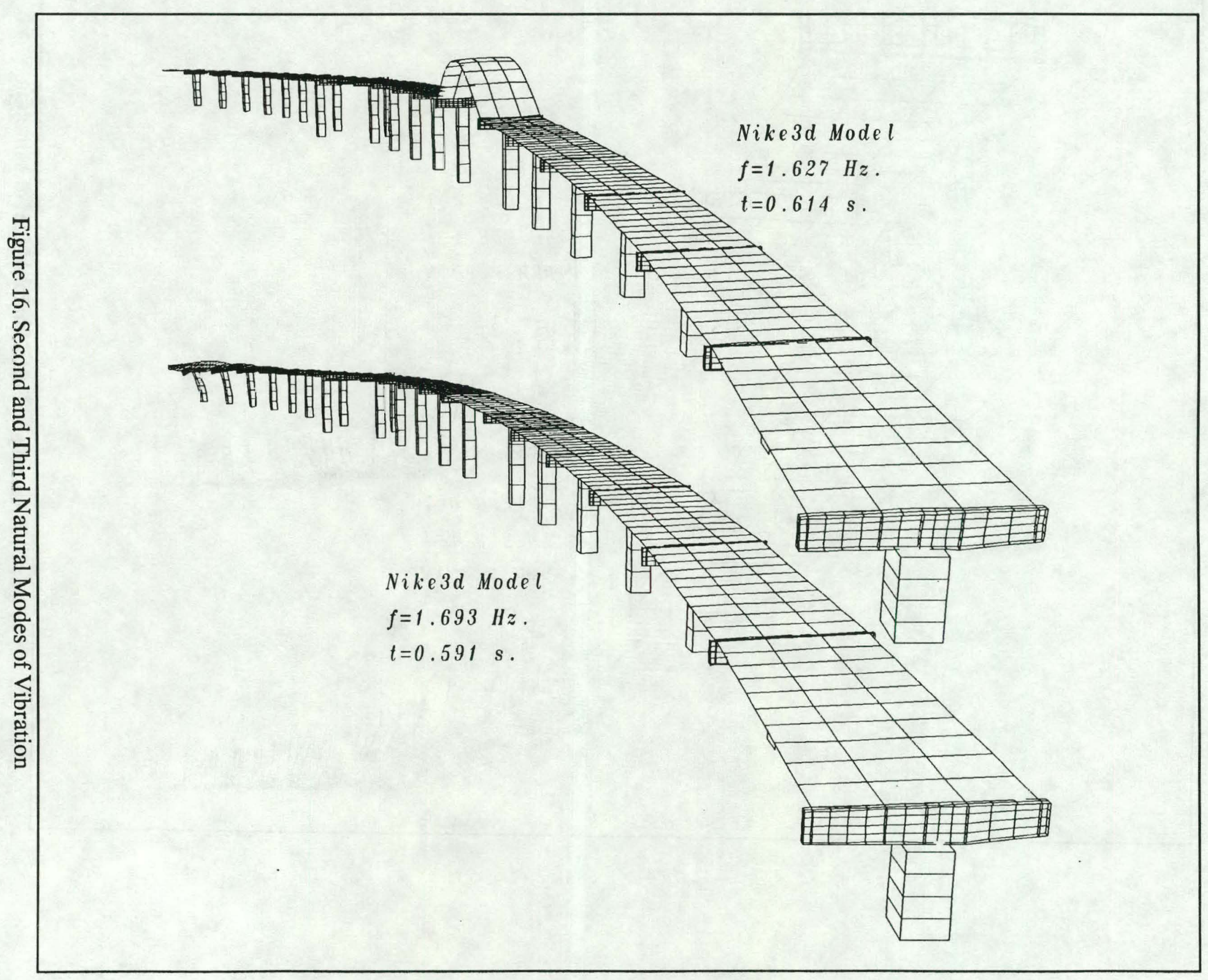




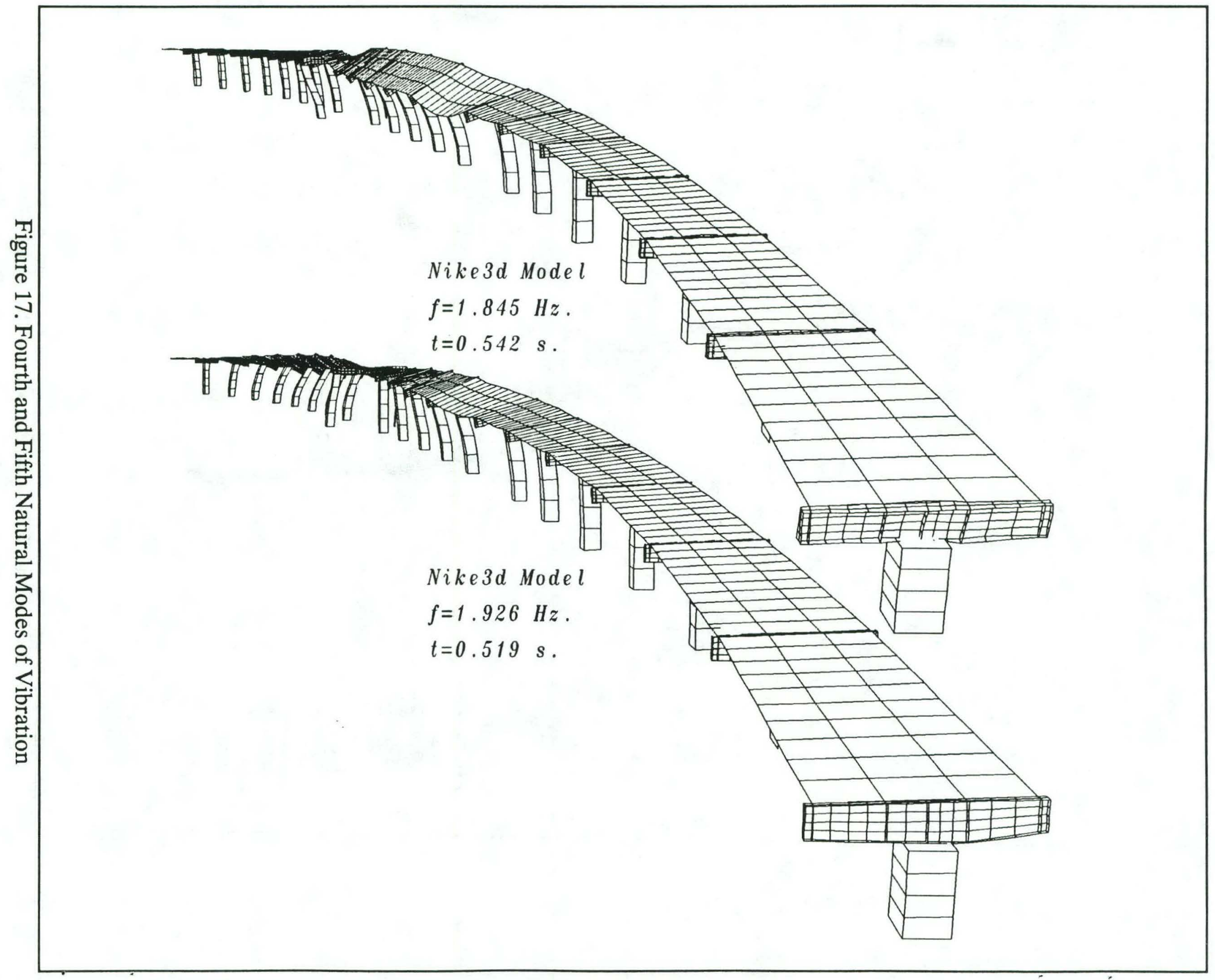


OMA PRIETA EARTHOUAKE TIME HISTORIES (OAKLAND WHARF)
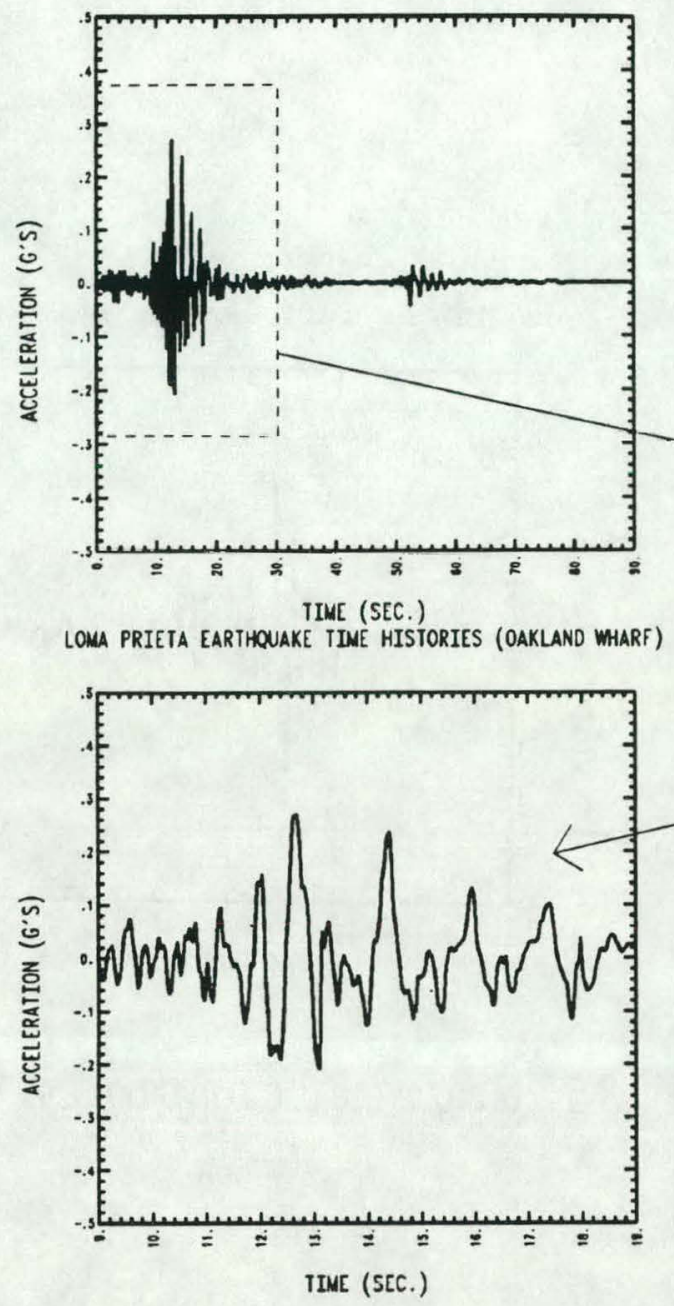

LOMA PRIETA CARTHQUAKE TIME HISTORIES (OAKLAND WHARF)

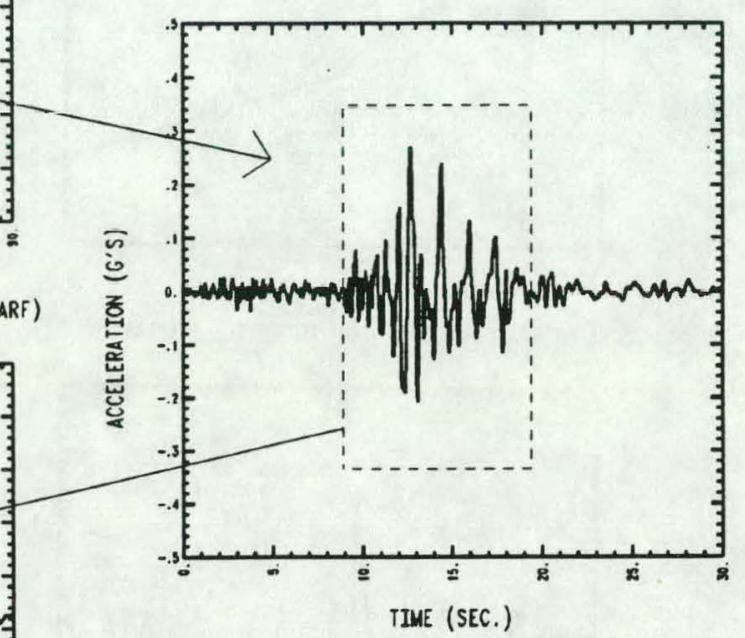

305 degree component

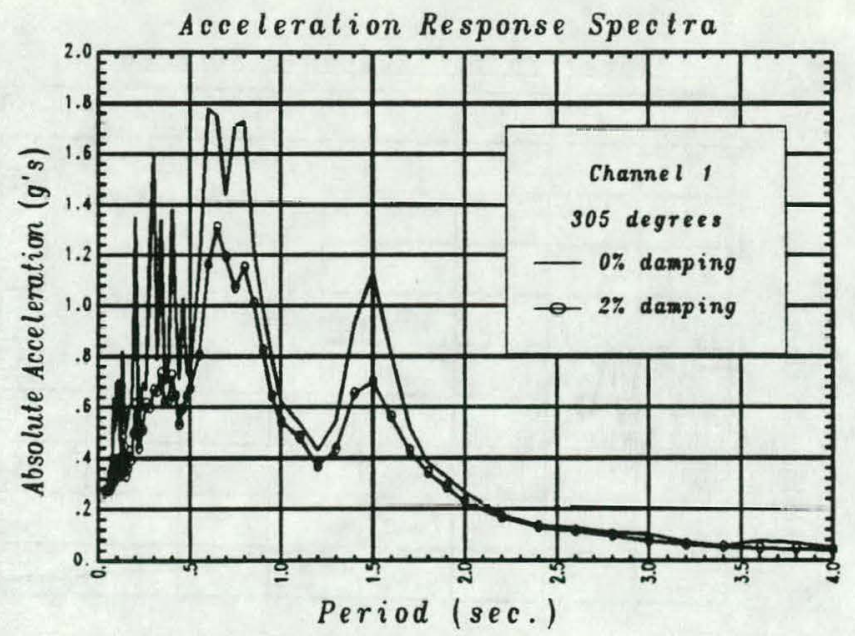

Figure 18. Acceleration Time History and Response Spectrum 
LOMA PRIETA EARTHOUAKE TIME HISTORIES (OAKLAND WHARF)

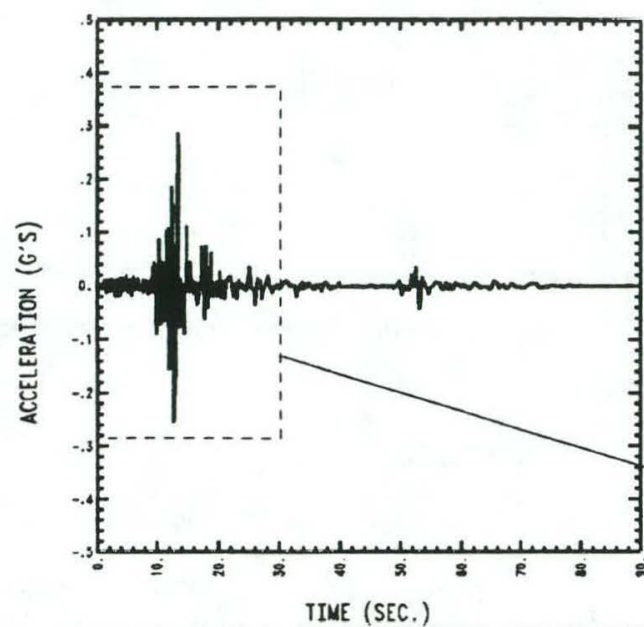

LOMA PRIETA EARTHQUAKE TIME HISTORIES (OAKLAND WHARF)

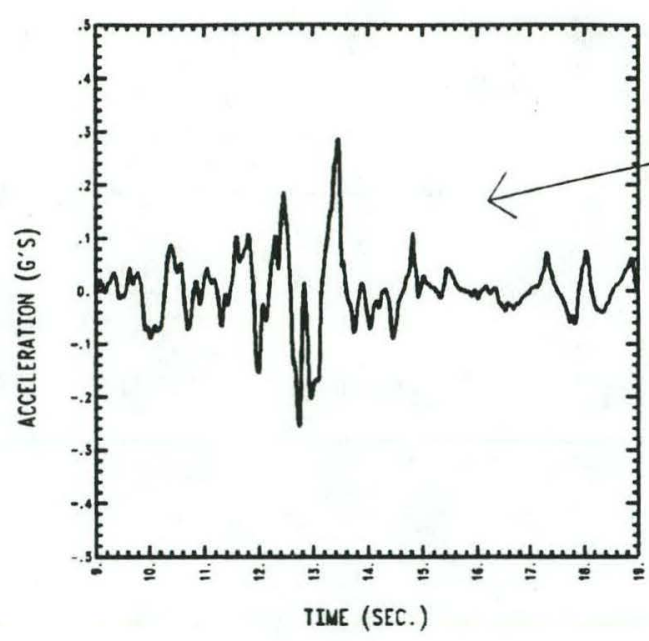

LOMA PRIETA EARTHQUAKE TIME HISTORIES (OAKLAND WHARF)

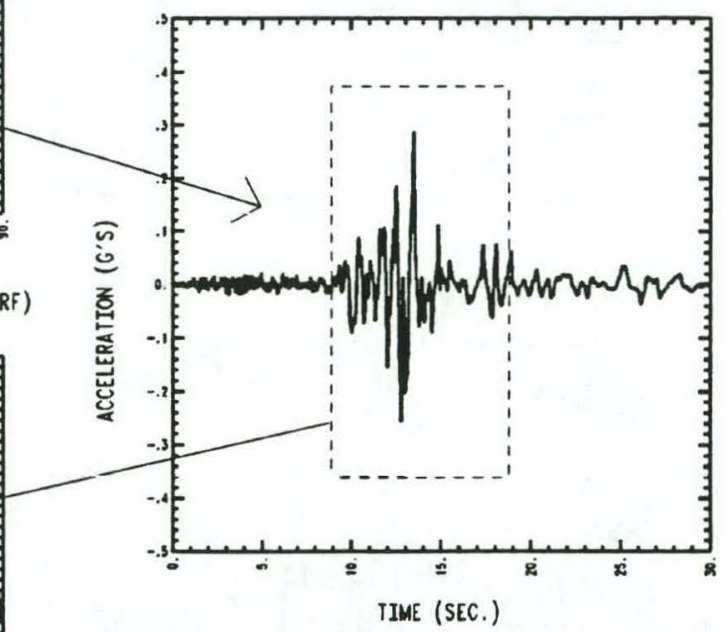

35 degree component

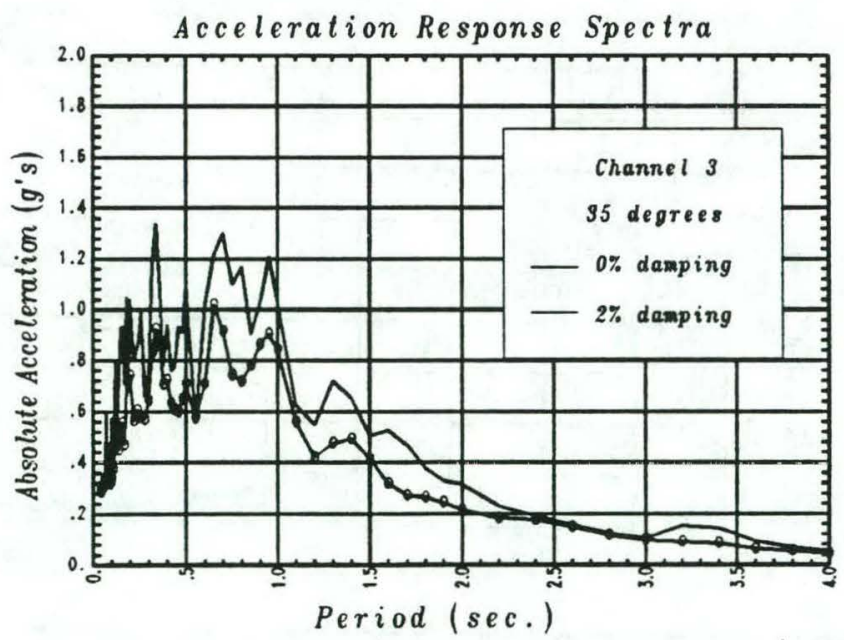

Figure 19. Acceleration Time History and Response Spectrum 
LOMA PRIETA EARTHOUAKE TIME HISTORIES (OAKLAND WHARF)

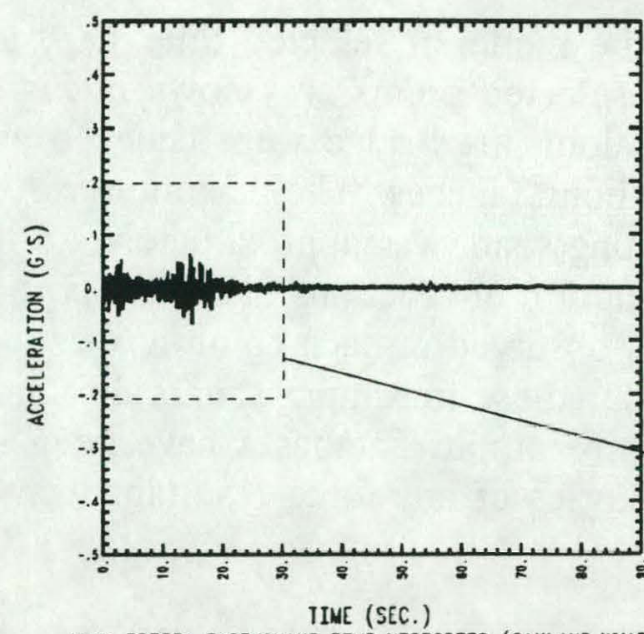

LOMA PRIETA EARTHQUAKE TIME HISTORIES (OAKLAND WHARF)

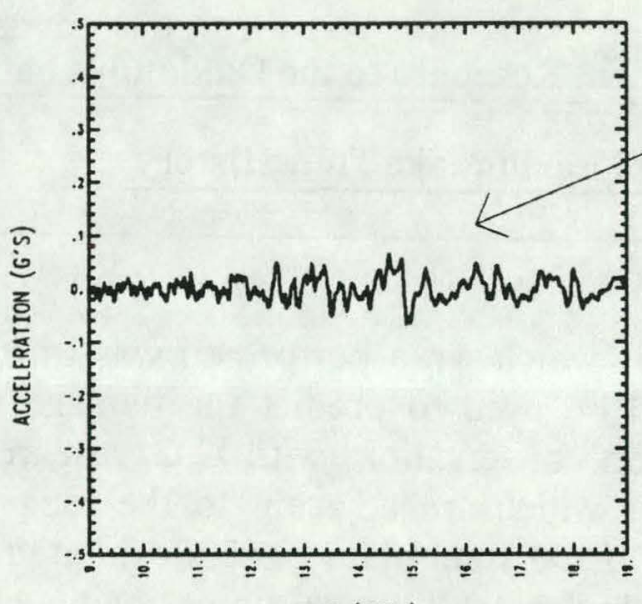

LOMA PRIETA CARTHQUAKE TIME HISTORIES (OAKLAND WHARF)

TIME (SEC.)

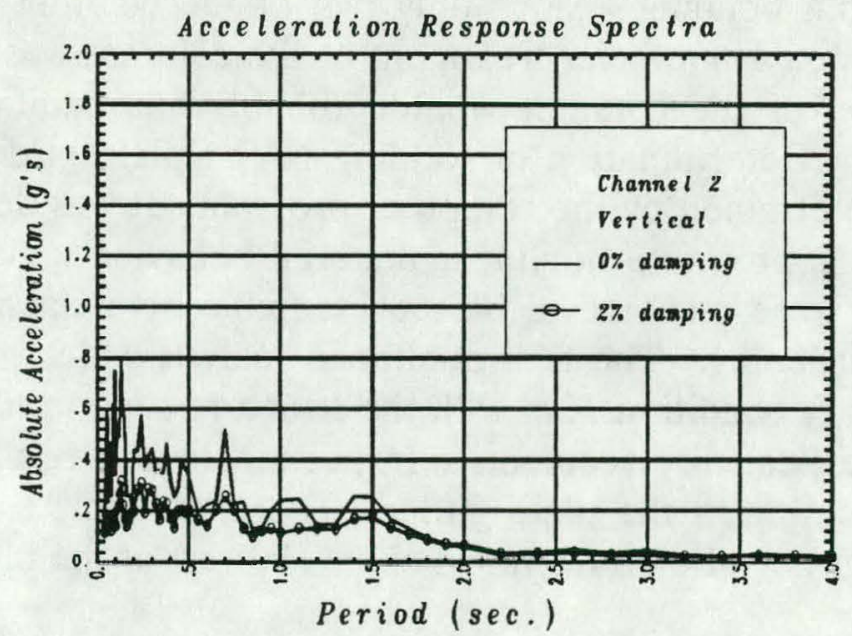

Figure 20. Acceleration Time History and Response Spectrum 
cause it allows the analyst to perform both linear and nonlinear analysis in an economical fashion without switching to a different program.

The exaggerated displaced shapes of the model at selected time steps are shown in Fig. 21 and displacement time histories at selected points are shown in Fig 22. The relative displacements at a number of points along the bridge were checked and the maximum observed transverse displacement was about 3 inches. The maximum vertical displacement, which occurs near the middle of the long span, was approximately 4.8 inches. Based on the transient analysis results, the distribution of reactions in the support columns was also examined. The maximum shear forces observed in each column over the duration of the entire time history are shown in Fig. 23 (these maximum shears do not necessarily occur at the same instant in time). The entire output databases have been saved from all of the time history analyses and time histories of any force resultants can be generated for future studies.

\subsection{Nonlinear Transient Response to the Oakland Wharf \\ Loma Prieta Earthquake Time History}

One of the objectives of the analyses which were performed was to investigate whether the LLNL nonlinear programs could be used to predict the damage which occurred in the structure being studied. Based on conversations with U.C. researchers, it was found that the reinforced concrete columns which are adjacent to the long span section were significantly damaged and a number of the steel plate girders exhibited permanent plastic deformation. Predicted failure of the indicated columns can be readily checked by utilizing the forces from the time history analysis together with ACI type interaction formulas for bi-axial column bending. Since only two of the columns were significantly damaged, it was decided that a nonlinear treatment of the columns was not necessary, and a nonlinear representation of the columns would probably not significantly change the reactions in the columns. Determination of yielding in the plate girders, on the other hand, is only practically determined by the computer program. It was decided to rerun the time history analysis with appropriate nonlinear material behavior specified for the plate girders. The plate girders were assumed to be representable by a classical elasto-plastic material with kinematic hardening. The first nonlinear analysis which was performed was for the first set of boundary conditions, i.e. with the structure supported at each end against horizontal as well as vertical displacements. Inspection of the results from this analysis indicated very little yielding in the plate girders. There was only a small region of minor yielding in the plate girder of the nontypical bent. The rest of the plate girders remained essentially elastic. 


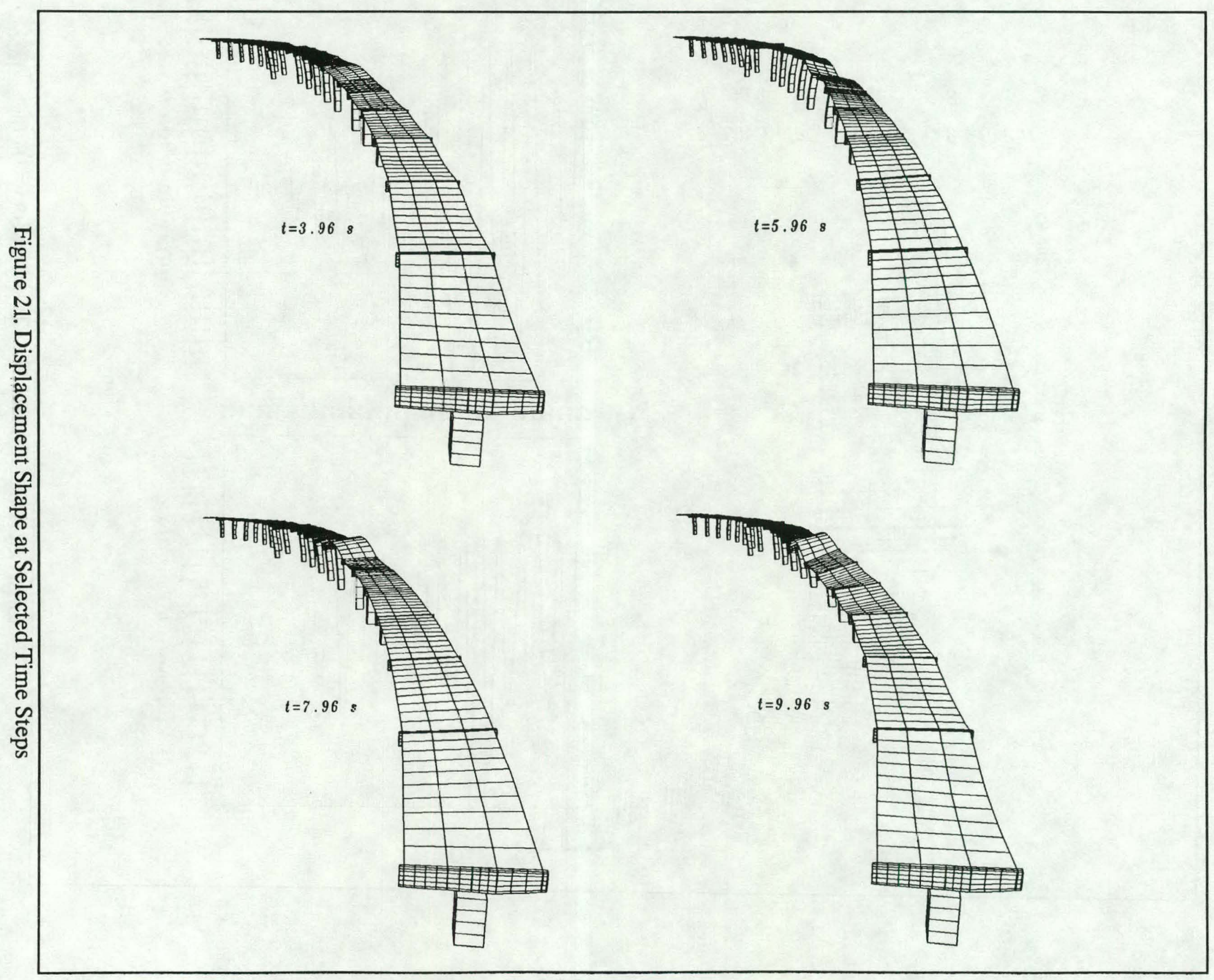




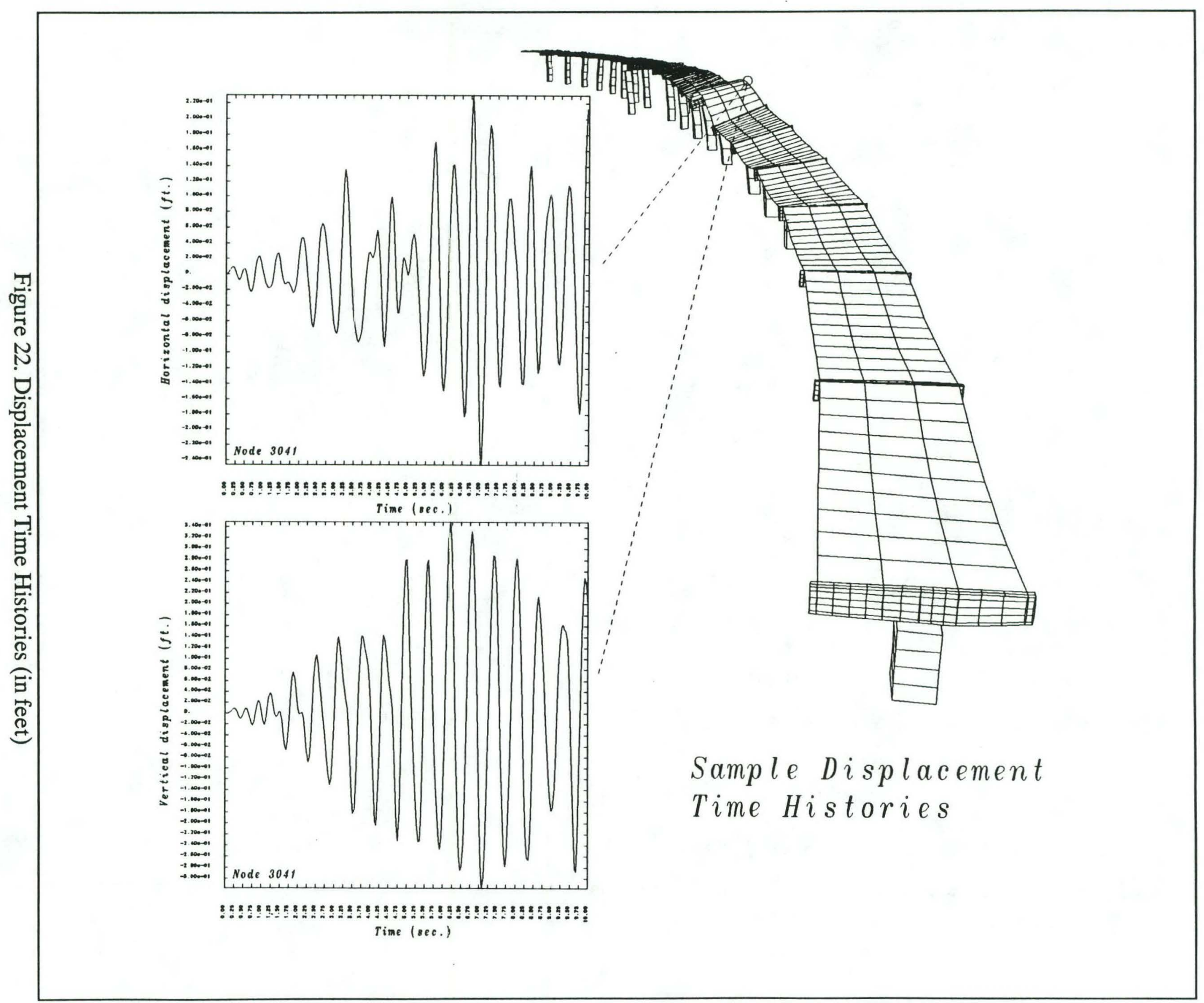




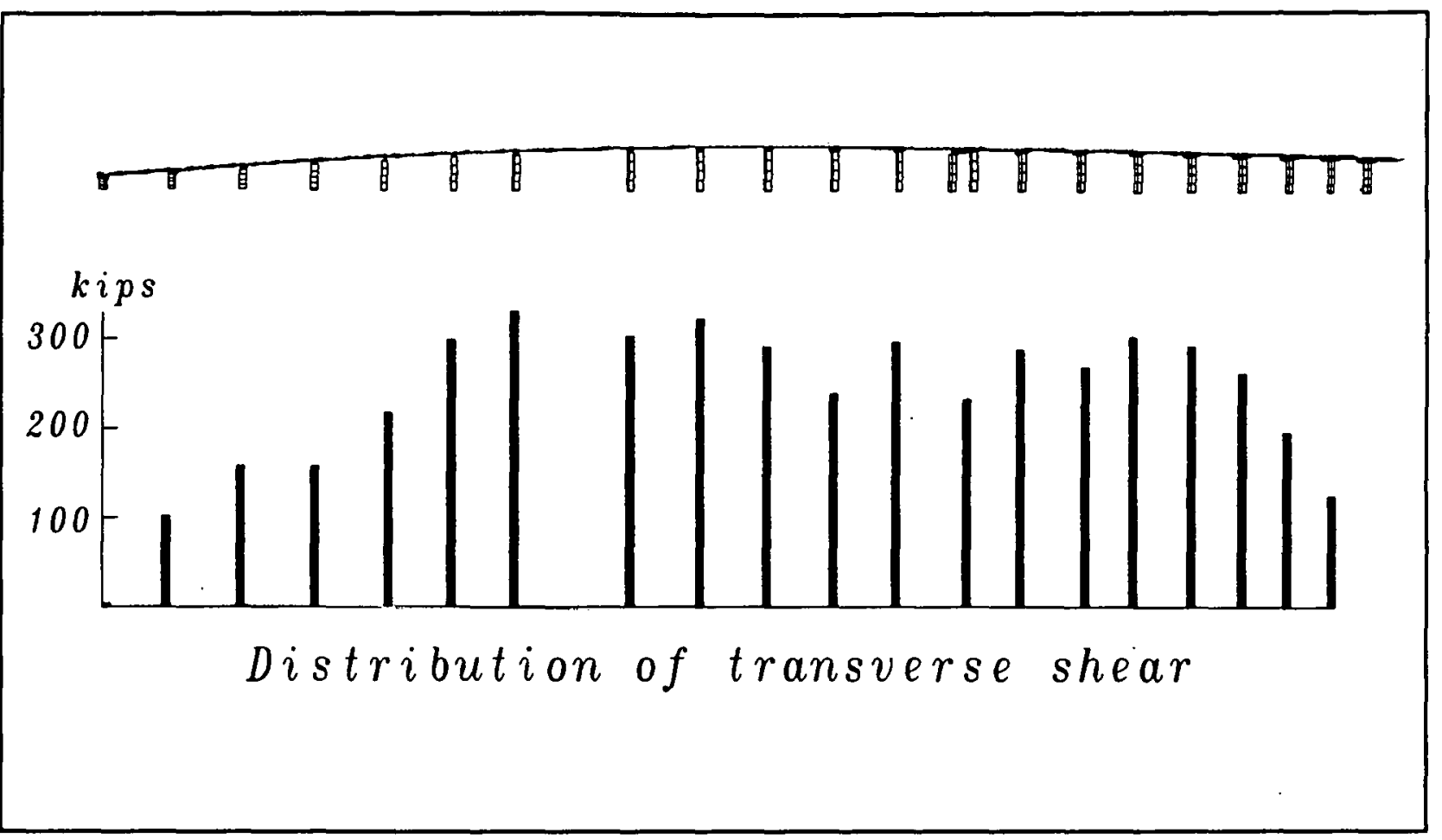

Figure 23. Maximum Shears at Column Bases

The second nonlinear analysis considered the alternate set of boundary conditions, that is, the boundary condition case in which longitudinal motion of the bridge structure was allowed. This analysis exhibited significant yielding in a number of bents. The regions of significant yielding for the second nonlinear analysis are shown in Fig. 24. The plate girders on the short end of the structure exhibited the most plastic strain. These girders are the ones subjected to the most severe out of plane bending as discussed in an earlier section (see also the fundamental longitudinal mode shown in Fig. 15). The results from the second boundary condition nonlinear analysis also exhibited horizontal deck displacements which were significantly larger than the displacements obtained for the first boundary condition case. The displacements for the nonlinear analysis with the second boundary condition set were on the order of 7.5 inches, compared to the 3 inches for the first boundary condition case (see Fig. 22). The vertical displacements did not substantially change between the first and second boundary condition cases (i.e. the maximum vertical displacements were about 4.5 to 4.9 inches for both cases).

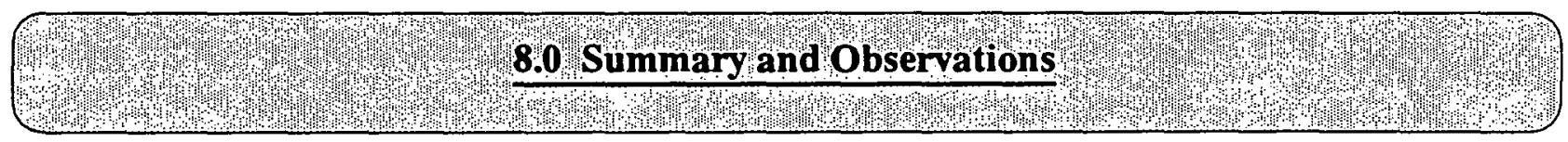

- Adequacy of LLNL software for modeling large civil engineering structures

The bridge structure which has been investigated offered a good opportunity for Livermore structural analysts to utilize LLNL software and L.LNL superçomputers on a large civil 


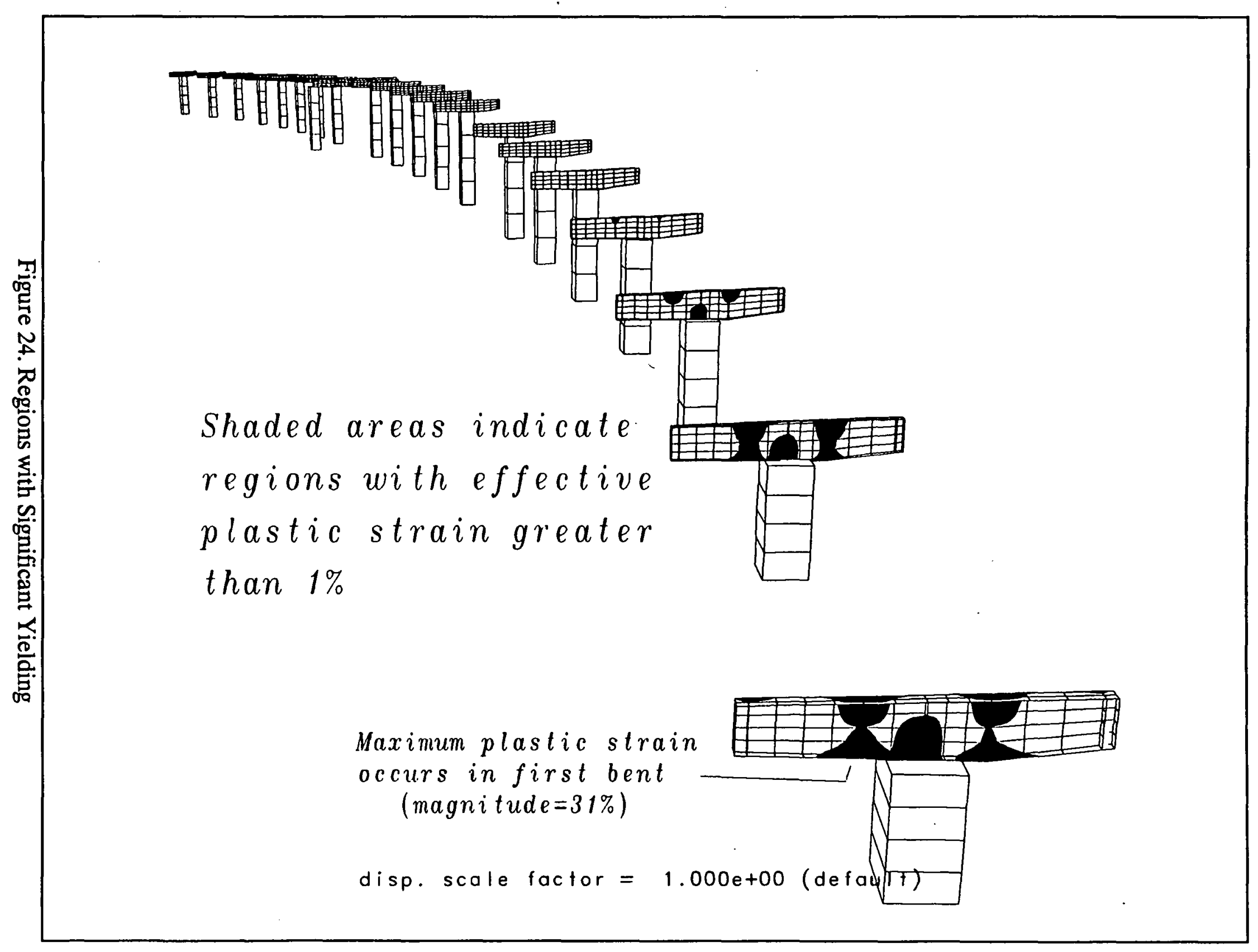


engineering structure. The feasibility of using the LLNL implicit finite element program NIKE3D was demonstrated. It was determined that NIKE3D (which does not have a specific option for linear small deformation problems) can be used economically for linear time history analysis. The equilibrium iterations at each time step converged so rapidly that the nonlinear nature of NIKE3D's algorithms was not a serious detriment. In addition, the nonlinear solution algorithm in NIKE3D proved very stable, with adequate convergence at all time steps, when significant nonlinear behavior occured.

\section{- Correlation between analysis results and observed damage}

There are a number of things which could be included in the existing structural model in order to improve the validity of the model (see discussion below), however, even with the existing model some observations can be made with regard to the observed damage. Based on conversations with Professor Astaneh, the columns adjacent to the long span section were most heavily damaged. The reaction distribution obtained in the linear analysis (see Fig. 23) does indicate that these columns are amoung the most highly stressed. An interesting additional piece of work would be to construct the 3 dimensional interaction surfaces for these columns and see if the observed stress levels from any of the analyses indicated failure.

Prior to this effort, Professor Astaneh and Professor Powell speculated that the structure must have sustained significant rocking motion about the columns. They based this observation on the nature of damage that was observed in field visits to the damaged structure. Figure 25 shows a picture drawn by Professor Astaneh in his early speculation about the motion required to generated observed damage. This observation correlates with the bent motion observed in the natural rocking modes which were observed in the structural model (see Fig. 25). Professor Astaneh also commented early on that based on observed damage, he thought longitudinal motion of the bridge caused some of the damage. The nonlinear analyses results for the two different boundary condition cases indicate that longitudinal motion can result in significant overstressing of some of the plate girders due to induced bending about their weak plane. There was little evidence of yielding in the plate girders until the longitudinal motion was allowed.

\section{- Additional enhancements to the finite element model}

There are some additional changes which can be incorporated in the model in order to better match reality. The compliance of the soil needs to be accounted for in the model. Based on measured soil properties, spring supports at the column bases could be estimated. Accounting for the soil compliance would increase the global flexibility of the structure with a corresponding increase in the natural periods of vibration. This could be significant in light of where the current modal periods fall on the response spectra. The current periods of the transverse modes of vibration of the structural model are in the range of 0.55 seconds and below (see Fig. 13 and Fig. 17). When these values are plotted on 


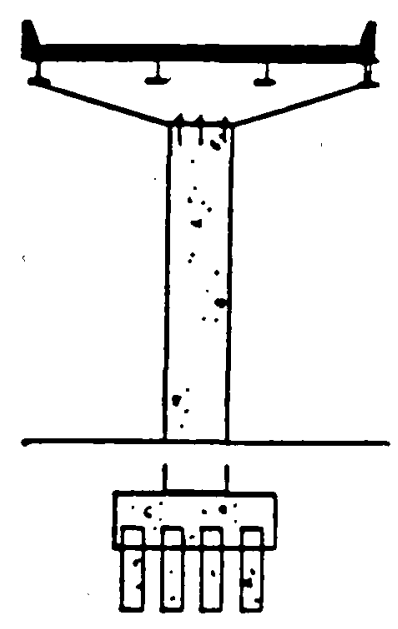

BEFORE EARTHOUAKE

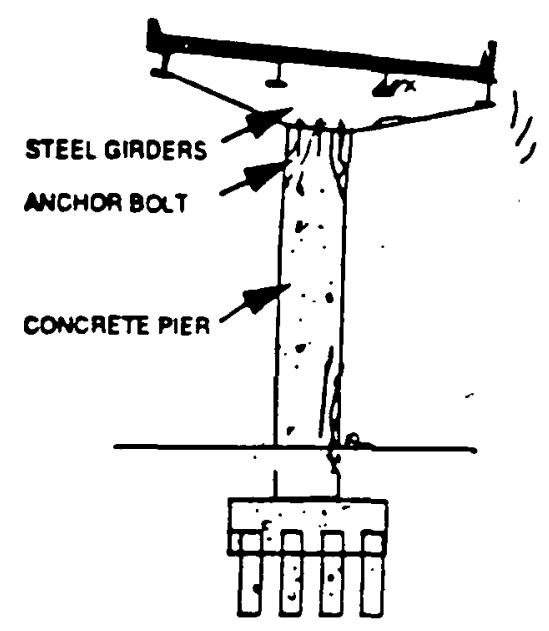

DURING

EARTHOUAKE

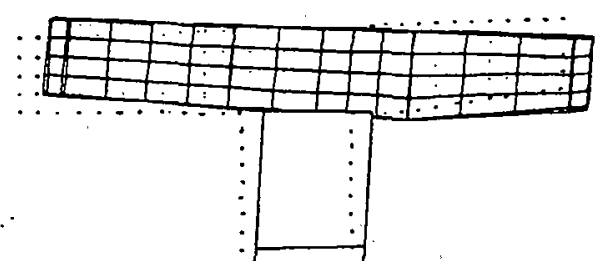

Column Motion

From Finite

E'lement Model

(1st Transverse Mode)

Figure 25. Suggested Motion Based on Observed Damage

the response spectrum, as shown in Fig. 26, it is seen that these periods fall just below the peak region on the spectrum. Increase of these modal periods would move these modes into the peak of the spectrum, with the result being a closer match between the frequency content of the ground motion and the natural frequencies of the structure.

\section{Acknowledgements}

The informational figures contained in the Background section of this resport were obtained from the United States Geological Survey Menlo Park office and the California Department of Mines and Geology. 


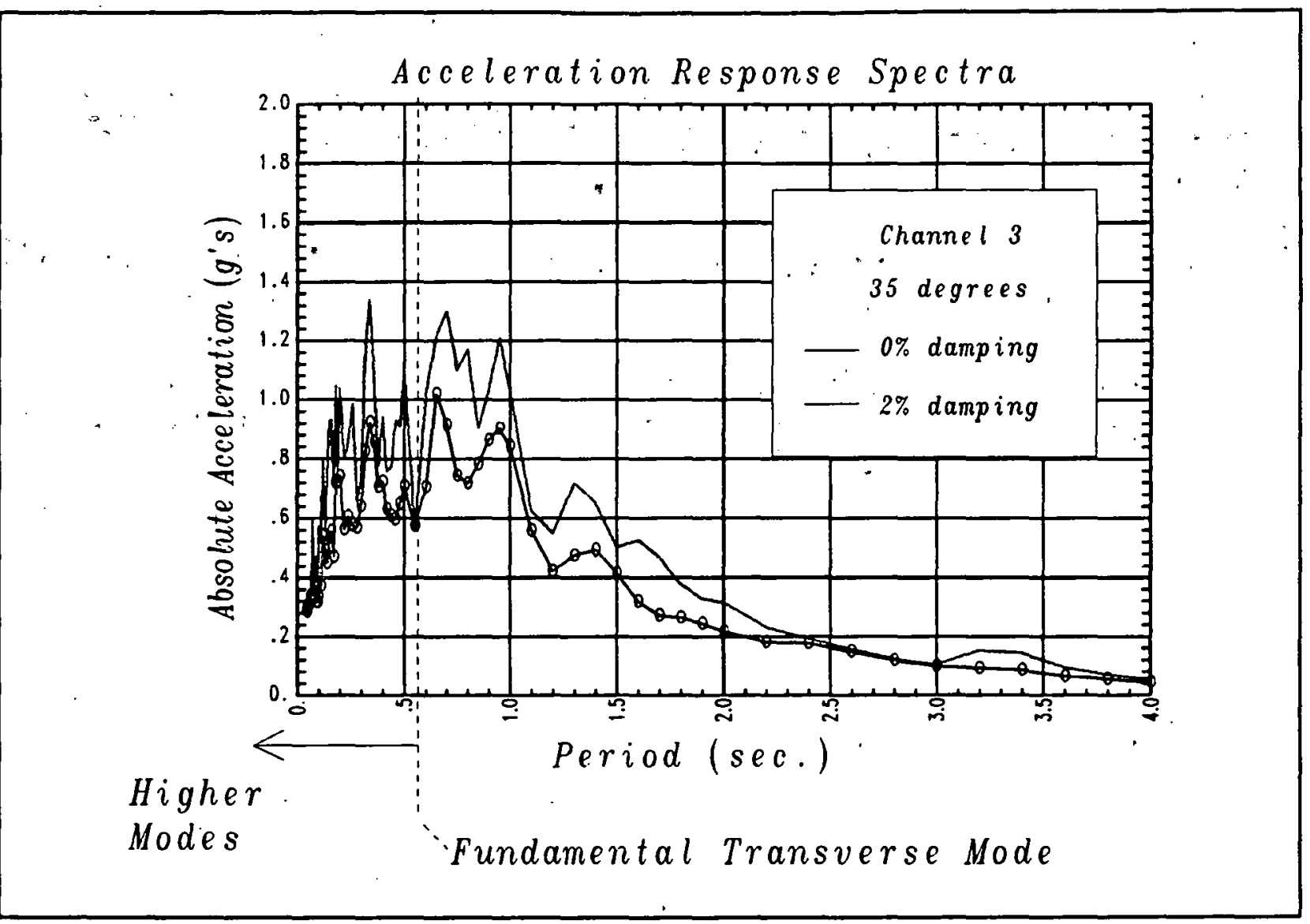

Figure 26. Location of Modal Periods Obtained from Model

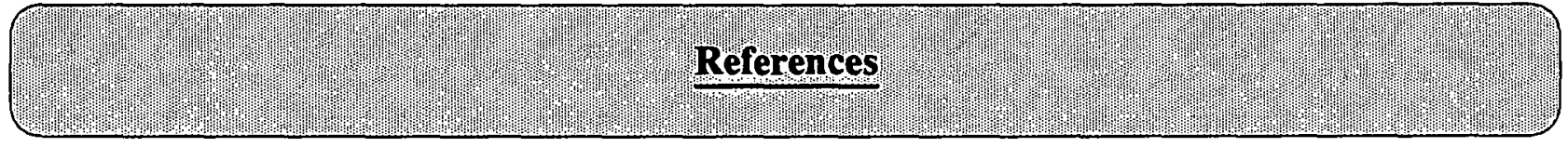

1) California Geology, California Department of Conservation, January 1990.

2) Engineering News Record, McGraw-Hill, February 22, 1990.

3) CSMIP Strong-Motion Records from the Santa Cruz (Loma Prieta), California Earthquake of 17 October 1989, California Department of Conservation Division of Strong Motion Studies Report OSMS 89-06, 1989.

4) M.A. Gerhard, SLIC/IV The Interactive Graphic Mesh Generator, Lawrence Livermore National Laboratory Report UCRL-52823, March 1989.

5) J.O. Hallquist, NIKE3D:An implicit, finite deformation, finite element code for analyzing the static and dynamic response of three-dimensional solids, Lawrence Livermore National National I aboratory Report UCID-18822, July 1984. 
6) T.J.R. Hughes and W.K. Liu, Nonlinear Finite Element Analysis of Shells:Part I., Three Dimensional Shells, Comp. Meths. Appl. Mechs., Vol. 27, p167-181, 1981

7) R.C. Murray, Gemini-A Computer Program for 2 and 3 Dimensional Linear Static, and Seismic Structural Analysis, Lawrence Livermore National Laboratory Report UCID-20338, October, 1984.

8) Personal communication between A. Astaneh, G. Fenves, R. Reimer and G. Goudreau, D. McCallen, University of California, Berkeley, February, 1990.

9) R.A. Imbsen, J. Penzien, Evaluation of Energy Absorption Characteristics of Highway Bridges Under Seismic Conditions, University of California at Berkeley, Earthquake Engineering Research Center Report EERC 84/17, September 1986. 
Technical Information Department - Lawrence Livermore National Laboratory University of California - Livermore, California 94551
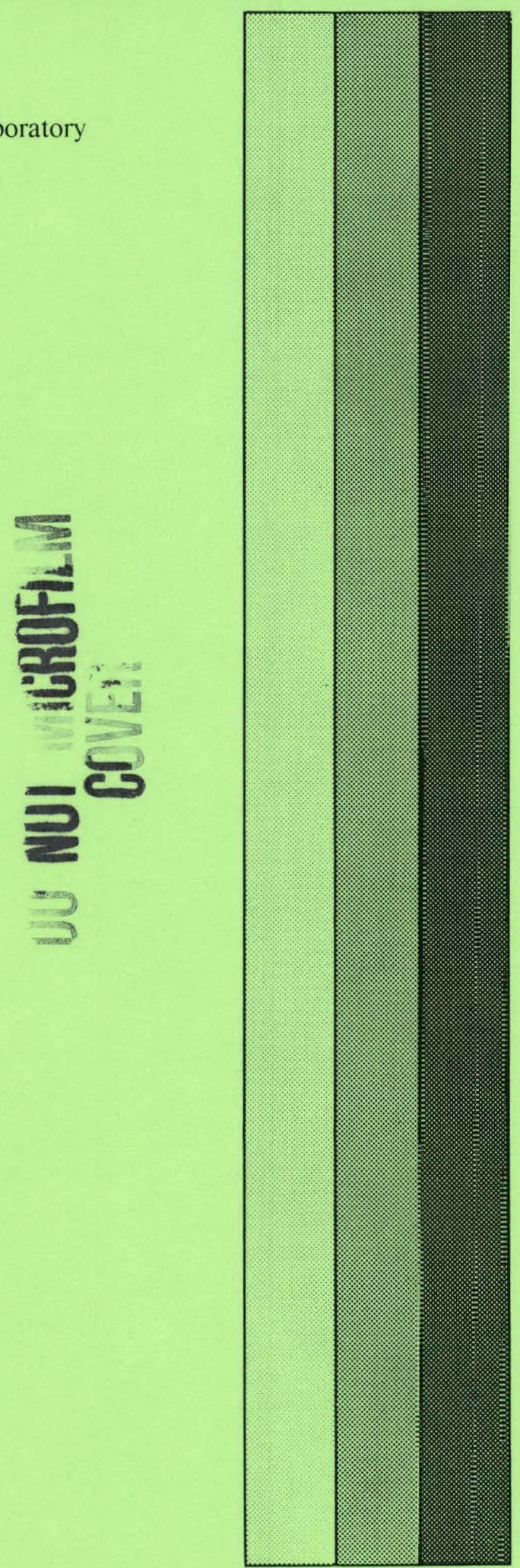